This PDF is a selection from a published volume from the National Bureau of Economic Research

Volume Title: Social Security Programs and Retirement around the World: Historical Trends in Mortality and Health, Employment, and Disability Insurance Participation and Reforms

Volume Author/Editor: David A. Wise, editor

Volume Publisher: University of Chicago Press

Volume ISBN: 0-226-90309-5; 978-0-226-90309-5

Volume URL: http://www.nber.org/books/wise11-1

Conference Date:

Publication Date: September 2012

Chapter Title: Health Status, Welfare Programs Participation, and Labor Force Activity in Italy

Chapter Author(s): Agar Brugiavini, Franco Peracchi

Chapter URL: http://www.nber.org/chapters/c12385

Chapter pages in book: (p. 175 - 215) 


\title{
Health Status, Welfare Programs Participation, and Labor Force Activity in Italy
}

\author{
Agar Brugiavini and Franco Peracchi
}

\subsection{Introduction}

Social protection is a central theme in the public policy debate, both because of a concern for protecting the welfare of individuals at different stages of their life cycles while reaching a certain degree of coverage and because financial sustainability of the social security system, under the demographic pressure, has become a major challenge. The present chapter describes the different Italian social protection programs that have provided resources to the elderly, trying to establish a link with longevity and the evolution of health conditions. Along with a description of the institutional setup and its relevant reforms, we describe the evolution of the main drivers: mortality and labor force participation. In the Italian context, access to oldage and early pensions has shaped the labor supply decisions of individuals, so we relate the evolution of health status to disability insurance participation as well as retirement pensions.

Our evidence, based on time series, cross-sectional and panel data, shows that the spectacular increase in longevity experienced by the Italian population in the last thirty to forty years has not lead to an increase in labor market participation. In fact, the "Italian paradox" is that higher longevity and improved health conditions are associated with a widespread detachment from the labor force. The main drivers of this behavior are the incentives

Agar Brugiavini is professor of economics at University Ca' Foscari, Venice. Franco Peracchi is professor of econometrics at the University of Rome Tor Vergata.

We are grateful to Fondazione Rodolfo De Benedetti (FRDB) for letting us use the INPS sample and to the Italian National Statistical Institute (ISTAT) for letting us use the MARSS data. For acknowledgments, sources of research support, and disclosure of the authors' material financial relationships, if any, please see http://www.nber.org/chapters/c12385.ack. 
embedded in the social security system that encouraged retirement, even at very early ages. This is clearly seen in the response to the pension reforms introduced during the 1990s, when a "retirement run" is observed as reforms are implemented - or even in the response to a reform announcement. It is worth stressing at the outset that, after the changes introduced in the mid1980s, disability pensions play a relatively minor role in Italy, representing less than 10 percent of the annual flow into retirement, the main and most easily accessible exit route from employment being early retirement.

The remainder of this chapter is organized as follows. Section 4.2 introduces the institutional characteristics of the welfare system in Italy and describes the main reforms in the Italian social security system. Section 4.3 presents some historical data on mortality and health status. This section provides a comprehensive overview of the patterns of mortality in Italy by gender and age-group, and their evolution over time, both at the national and the regional level. The analysis of the mortality patterns by birth cohorts and causes of death also tries to emphasize the possible sources of the gains in longevity. Section 4.4 presents labor force and social security program participation in Italy over time and by age-group. The aim is to establish how the reforms of the social security system affected participation behavior and the take-up of the different benefits. We exploit information on new entries into the public pension and the disability insurance system to better understand the immediate and the long-term effects of the reforms on workers' retirement decisions. This section also analyzes the various pathways to retirement, making use of the panel dimension of the data. We follow different cohorts of individuals who, throughout their working lives, experienced different social security arrangements and different reforms. Section 4.5 relates historical data on employment, disability, and retirement to mortality and evolution of the health status. Finally, section 4.6 concludes.

\subsection{History of Reforms}

The Italian welfare system is characterized by high spending on retirement pensions relative to unemployment benefits and disability provisions. Pension expenditures represent 15.2 percent of the gross domestic product (GDP) in 2007, a fraction that is still increasing partly as a result of the recent recession (RGS 2009). Old-age and early retirement pensions alone account for 10 percent of GDP, survivor pensions for 2 percent, total disability and invalidity pensions together for just 1.7 percent, with the rest being other forms of income support for the elderly. Unemployment benefits represent only 0.5 percent to 0.6 percent of GDP, and other social areas are also negligible (ISTAT 2010; OECD 2009). It is clear that, in Italy, old-age pensions crowd out other social expenditures such as unemployment benefits.

Several reforms of the welfare system have taken place over the years, but 
the most important ones have been in the area of public pensions. In this section we briefly review these reforms. ${ }^{1}$

\subsubsection{Institutional Features of the Social Security System}

Because the basic historical aspects of the system are well documented (see, for example, Brugiavini, Peracchi, and Wise [2003]; Brugiavini and Peracchi [2004]), in this chapter we only describe briefly its main rules and recent developments (see also OECD 2007).

The Italian social security system is based on a variety of institutions administering pension programs for different types of workers (privatesector employees, public-sector employees, self-employed, professional workers). ${ }^{2}$ All programs are of the unfunded pay-as-you go (PAYG) type. Despite a process toward convergence during the 1990s, the various programs maintain quite different rules. In terms of pillars, the first pillar is the most relevant. It ensures against three types of risks: longevity (old age and early retirement benefits), death (survivor benefits), and disability (disability benefits). ${ }^{3}$ The second and third pillars have been encouraged by some legislative acts, but never actually implemented. Currently, about two-thirds of the labor force is insured with the National Social Security Institute (INPS). The Institute is responsible for a number of separate funds, of which the most important (Fondo Pensioni Lavoratori Dipendenti [FPLD]) covers the private-sector, nonagricultural employees.

The system started before World War I, but was redesigned in 1969: social security benefits changed from a defined-contribution to an earningsrelated social insurance system. The aim was to guarantee to every retired worker an income comparable to that earned during the working life. At the same time, coverage increased. An early retirement pension was introduced, which also guaranteed a retirement income to individuals with at least thirty-five years of contribution, irrespective of age. The way benefits were computed changed over time, but was essentially of a final salary type, as average earnings over the last years of work (pensionable earnings) formed the basis for the calculation. To pensionable earnings, a rate of return (representing the accrual factor) was applied: a parameter approximately equal to 2 percent for each year of contribution. ${ }^{4}$ Until 1968, an old-age pension could not be combined with earnings, but this restriction was lifted in 1969, albeit within limits. Again in 1969, pension benefits were automati-

1. "Social security" and "pensions" in Italy have the same meaning, as there is essentially no second or third pillar yet (and certainly not in the period under investigation).

2. Social security system and pension system are used as synonyms in this chapter. In fact, social security is the main source of publicly provided income in old age in Italy.

3. In Italy, disability pension refers to more than one type of pension. See section 4.2 .2 for more details.

4. The rate was initially lower and grew over time. 
cally indexed to both inflation and part of the wage growth. In 1976, they were automatically indexed to the contractual wages of the workers in the industrial sector. The eligibility age for old-age benefits was sixty for men and fifty-five for women though, as already mentioned, a generous early retirement option was available. As for public-sector employees, benefits calculations were even more generous than in the private sector, as the earnings immediately prior to retirement formed the basis of the benefit. Further, men and women could take early retirement with just twenty or fifteen years of contributions, respectively.

\subsubsection{Reforms of the Social Security System in the 1990s}

While minor changes in the rules took place very frequently throughout the 1970s and 1980s (almost invariably increasing the generosity of the system), major reforms of the social security system took place in 1992, 1995, and $1997 .{ }^{5}$ They are known, respectively, as the Amato, Dini, and Prodi reforms, from the names of the prime ministers at the time. Further changes to the system have been made nearly every year since 1992. Of the three main reforms of the 1990s, the Dini reform appears as the most radical, because it completely redesigns the system by modifying the eligibility rules and by changing the benefit formula from defined-benefits to notionally definedcontributions. However, because the changes are only introduced gradually, through a very long transitional period, the direct effects of the Dini reform were lower compared to the less radical Amato reform.

An important aspect of the reforms of the 1990s is the differential treatment of different cohorts of workers. The Amato (1992) reform explicitly distinguishes between workers with at least fifteen years of contributions at the end of 1992 and all other workers. The old (1969) system applied to the former group, whereas the new system applied to the latter. Under the new system, the eligibility age for an old-age pension was to increase gradually by one year of age every two years, starting from 1994, until reaching age sixty-five for men and age sixty for women in the year 2000. The eligibility age was instead immediately set at age sixty-five for state employees and age sixty for local government employees, irrespective of gender. The number of years of contribution required for an old-age pension was to increase gradually by one every two years starting from 1993, until reaching twenty years of contributions in 2001. For workers with less than fifteen years of contributions at the end of 1992, the reference period for computing pensionable earnings was to increase gradually to include the whole working life, with past wages adjusted to inflation on the basis of the annual rate of change of the cost-of-living index plus an additional 1 percent. One important change,

5. See also Brugiavini and Peracchi (2004), Brugiavini and Galasso (2004), and Brugiavini (2009). 
aimed at curtailing the generosity of the system, was indexation of pension benefits only to price inflation, not to wage growth.

The differential treatment of older and younger workers was maintained in the subsequent Dini (1995) and Prodi (1997) reforms. The Dini reform distinguished between three categories of workers depending on their number of years of contribution at the end of 1995: (a) those with at least eighteen years, (b) those with less than eighteen years, and (c) new entrants to the labor force. Except for the changes to the eligibility rules introduced by the Amato reform, very little changed for workers with at least eighteen years of contributions. On the other hand, for new entrants, the Dini reform changed dramatically the benefit computation method from definedbenefit (DB) to notionally defined-contribution (NDC). For workers with less than eighteen years of contributions, benefits would be calculated on a pro rata basis according to the number of years of contributions under the two regimes (contributions paid after 1995 count under the new regime). The Dini reform also modified the existing rules on early retirement by introducing a dual requirement in terms of age and years of contribution: starting from 1996, a worker with thirty-five years of contribution could retire only if aged fifty-two or older. This limit was raised gradually until reaching age fifty-seven in 2002 for both men and women (similar, though slightly different rules applied to public sector employees). The minimum number of years of contribution was also increased gradually until reaching forty years in 2008. Since the eligibility rules for old-age and early retirement pensions are driving the behavior of workers during the period that we consider, tables 4.1 and 4.2 summarize their year-by-year changes for the two main funds of INPS, private employees (FPLD), and artisans and traders.

By far the most important change of the Dini reform was the change in the benefit computation method from DB to NDC for the new entrants into the labor market. For these workers, the pension is to be based on a notional contribution equal to 33 percent of covered annual earnings in the case of employees (only 20 percent in the case of the self-employed). Cumulated notional contributions earn an annual return equal to the average rate of increase of gross domestic product (GDP) during the past five years. At retirement, the lifetime accrued notional stock of contributions is converted into a pension through an actuarial coefficient that varies depending on the worker's age (from 4.720 percent at age fifty-seven to 6.136 percent at age sixty-five). Since a pro rata system applies to the benefit calculation for workers with less than eighteen years of contributions at the end of 1995, actual benefits also vary depending on the year of entry into the labor market. As for collecting benefits while working, the new rules allowed combining benefits with earned income, subject to some limitations. The pre-1995 regime also included a minimum pension, which was later abolished for workers entering the labor market after 1995 (under the new regime, retirees 


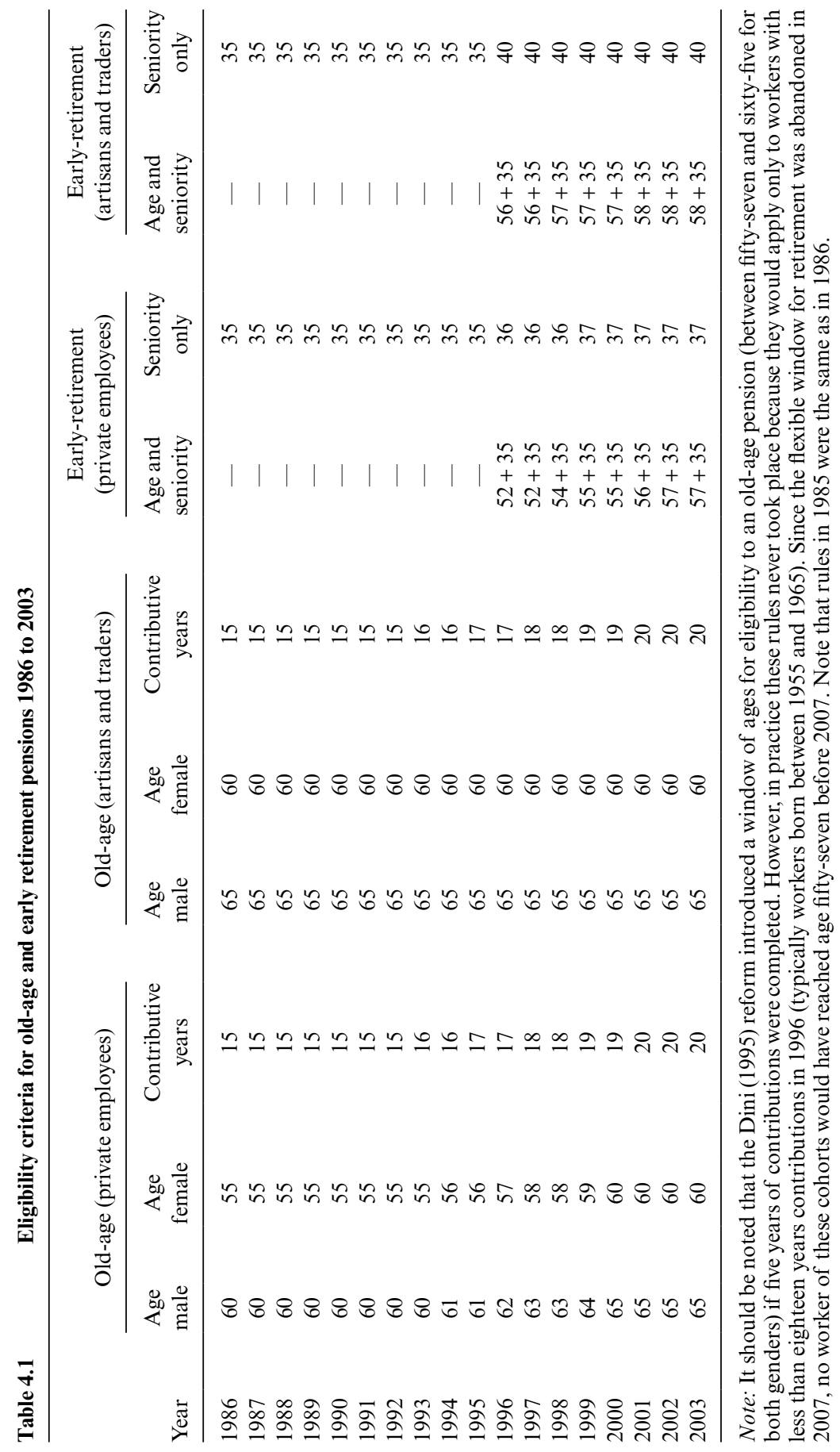


with total incomes below the social-assistance level can claim a meanstested social benefit from age sixty-five).

\subsubsection{Disability Insurance}

A public invalidity pension was introduced in 1919 for individuals who, because of reductions in their working capacity, were unable to earn income below a certain amount, equal to one-third of the normal wage for a worker in the same activity in the same area of the country. In 1984, the public invalidity pension was modified as to cover individuals with a certified mental or physical impairment, which reduces their working capacity by twothirds. Also, a public inability pension was introduced for private-sector employees and self-employed workers with a physical or mental disease, certified by a medical test, which is permanent and makes it impossible to carry out any job. With the Dini (1995) reform, the public inability pension was extended to public employees under the proviso that the impairments are not caused by work (a special inability pension for the public sector already existed, which provides for income support in the case of workcaused impairments).

Currently, the Italian social security system provides two types of disability benefits:

1. Ordinary ("civilian") disability benefit, granted to all citizens under certain health impairments (including deaf or dumb people older than eighteen). In some cases, a monthly attendance benefit is also paid in order for the beneficiary to receive home care. For people older than sixty-five, a non-contributory pension is paid ( pensione sociale). Since 1971, an inability pension is also envisaged for individuals who cannot carry out any type of work, at ages between eighteen and sixty-five. The handicap should be certified to be 100 percent of the working capacity of the individual.

2. Invalidity benefit, granted to workers registered with the Italian social security administration (INPS) whose working capacity is permanently reduced by at least two-thirds because of physical or mental impairments.

The important landmark in terms of reforms was a law passed in 1984 establishing that an invalidity pension could be granted only if the physical or mental disease was certified by a medical test. Furthermore, at least five years of social security contributions were necessary, of which at least three were paid during the five years before applying for benefits. The important restriction introduced in 1984 was that the invalidity pension was no longer a permanent pension but should be renewed every three years, becoming permanent only after three renewals. It would also be automatically converted into an old-age pension at the legal retirement age and could not be paid along with unemployment benefits. On the other hand, inability pensions are permanent (not subject to renewal) and never become old-age pensions. Further small restrictions were introduced later on. For example, 
starting from 1995 the disability pension cannot be collected along with the life annuity (INAIL life annuity) granted in case of job injury.

\subsubsection{Unemployment Insurance}

The Italian unemployment insurance system differs substantially from that of other countries in both the eligibility conditions and the amount and duration of the benefit. The system currently provides income only to workers who lost their job, not to first-time job seekers. Contributions to the system are paid by workers and employers at differential rates (in the industrial sector 4.71 percent of gross wage, of which 4.41 percent falls on the employer). The system offers two different schemes:

Comprehensive insurance (UI)

Ordinary unemployment benefit

Special unemployment benefit

Mobility benefits

Partial Insurance

Cassa Integrazione Guadagni Ordinaria (CIGo)

Cassa Integrazione Guadagni Straordinaria (CIGs)

Unemployment insurance (UI) benefits are paid to workers individually laid off in the private sector or collectively laid off, not eligible for other benefits, and who have paid contributions for at least fifty-two weeks during the twoyear period preceding unemployment. ${ }^{6}$ Some benefits may also be claimed by those who worked at least seventy-eight days over the last year (reduced requirement). Ordinary UI benefits are paid on a seven-day-a-week basis, for a maximum of one hundred eighty days (extended to eight months since January 2008). For unemployed aged fifty and older, the duration has recently been extended from nine to twelve months. Furthermore, the benefit is stopped if the beneficiary gets a new job or refuses a job similar to the lost one, or does not accept to be employed in a socially useful job. Benefits are paid as a percentage of the average wage in the last three-months-wage, with some ceilings imposed. For example, ordinary UI benefits are 60 percent of the average wage for the first six months, 50 percent for the seventh and eighth month, and 40 percent for the subsequent months, up to a maximum level of $€ 886$ for wages below $€ 1,917$, and $€ 1,065$ for wages above that figure.

Cassa Integrazione Guadagni (CIG) is a wage supplementation fund for workers in industrial firms with fifteen or more employees (workers in industrial firms with less than fifteen employees and in most of the services are excluded). Workers on CIG formally retain an ongoing work relationship, as their contract has not been terminated, so they do not enter the official unemployed count. Still, we think that CIG is relevant for two reasons. First,

6. Young workers in vocational training are excluded. 
in survey data, individuals may report themselves as unemployed if they receive CIG benefits. Second, a broad definition of unemployment should also include these beneficiaries. Ordinary benefits (CIGo) are paid to workers for foregone hours of work (also at zero hours) due to the temporary reduction of the firm's activity. The CIGo benefits are normally paid for a maximum of thirteen months (under special circumstances, up to fifty-two weeks). The replacement rate is 80 percent of the wages foregone. Special benefits (CIGs) are paid when reduction of the activity is not temporary, but is due to sector- or area-specific firm restructuring. The CIGs benefits are normally paid for twelve to twenty-four months (the length depending on the type of difficulties that the firm faces as well as on the restructuring strategy). Some extension may be obtained if restructuring lasts for more than twenty-four months. In any case, CIGs benefits cannot be paid for more than thirty-six months over five years. Workers (except those in the construction industry) who formerly benefited from CIGs are available for the mobility benefits under the UI scheme. Hence, mobility benefits represent a follow up to CIG.

\subsection{Historical Data}

\subsubsection{Mortality}

This section reviews the historical trends and the current patterns of mortality among the elderly in Italy.

Our data come from two sources. The first is the Human Mortality Database (HMD), which contains annual mortality rates broken down by gender and single year of age. The HMD data are derived from official vital statistics and census counts published by the Italian National Statistical Institute (ISTAT) and refer to the country as a whole. They cover the period from 1872 to 2006 , thus offering a long-term view of the time trends of mortality in Italy. However, because the quality of the data for the early period 1872 to 1905 is lower than in later years, we confine ourselves to the period 1906 to 2006. Our second data source is the sequence of annual life tables for the period 1974 to 2006, broken down by gender and region of residence, compiled by ISTAT. These data offer a detailed geographical description of the changing patterns of mortality over the last three decades.

\section{Secular Trends}

Figure 4.1 shows the secular trend of mortality at four different ages (forty, fifty, sixty, and seventy), respectively for females and males. Mortality rates are in percentage terms and the vertical lines in the figures mark the periods 1915 to 1918 and 1940 to 1945 , which correspond to World War I and World War II, respectively (notice that Italy entered both wars one year later). Figure 4.2 displays the same data in a different format by showing the 

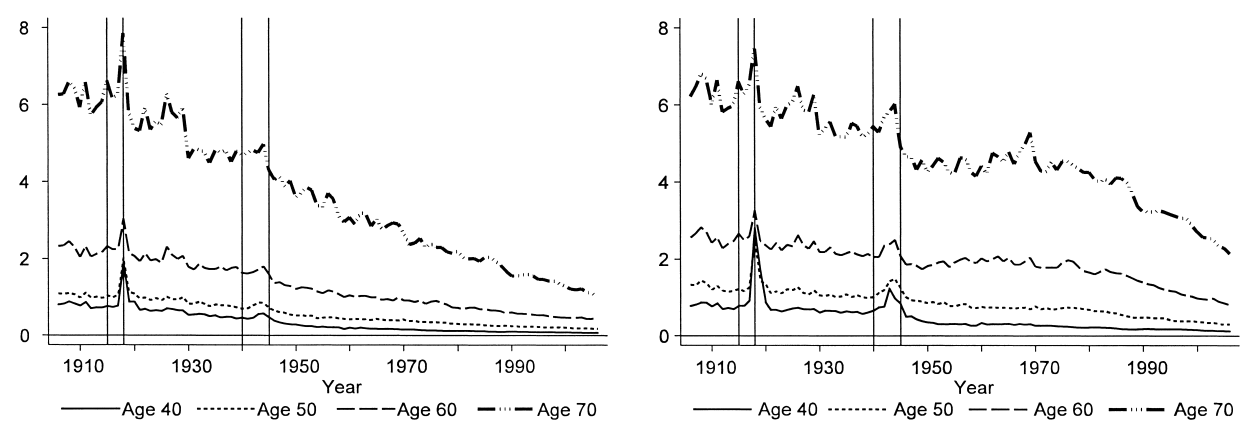

Fig. 4.1 Mortality rates over time (women left, men right)
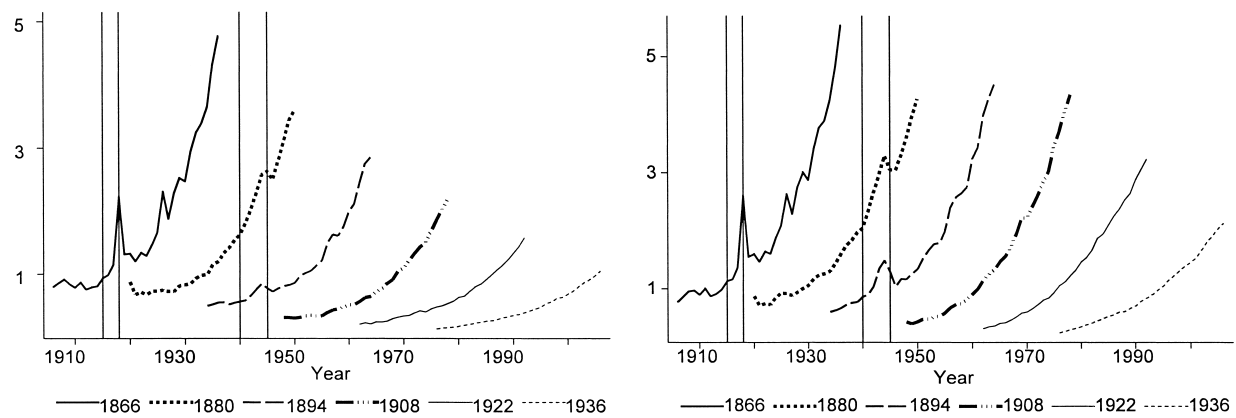

Fig. 4.2 Mortality rates by birth cohort at ages forty to seventy (women left, men right)

profiles of mortality for females and males belonging to six different birth cohorts (born in 1866, 1880, 1894, 1908, 1922, and 1936). This figure helps us appreciate the changes across cohorts in the profile of mortality between age forty and age seventy.

If we ignore the sharp spike corresponding to the last years of World War I and the post-war influenza pandemic and the spike corresponding to World War II, the figures are dominated by the dramatic decline of mortality for both females and males. It is worth pointing out at the outset that, except for its timing and intensity, mortality decline in Italy follows a pattern that is qualitatively similar to that observed in all industrialized countries. As a consequence of the mortality decline, life expectancy at birth has risen from about forty-five years for both men and women in 1906 to seventy-eight years for men and eighty-three years for women in 2006, with a gain of thirty-three life years for men and thirty-eight for women. At age sixty the gain in life expectancy is 7.6 years for men and 11.5 years for women, while at age eighty the gain is 3.2 life years for men and 4.9 for women. In 1906, both men and women reached the 5 percent mortality rate at age sixty-nine, while in 2006 the 5 percent threshold is reached by men at age seventy-eight, 
that is seven years later, and by women at age eighty-three, that is fourteen years later.

Mortality first began to shrink in the early decades of the 1900s. Between 1906 and 1931 men gained 8.9 life years at birth and women about 10.5. Between 1931 and 1956, survival takes another major leap, with men gaining 11.7 extra life years at birth and women 14 extra years. During this period, the main contribution to the trend comes from the decline in infant and youth mortality, largely due to the progressive eradication of infectious diseases. The rapid decline in infant and youth mortality in the first part of the 1900s contrasts sharply with the marginal gains in male survival at later ages: for adult males very little changes are registered before World War II. The reduction in adult male mortality begins only later, during the 1950s and 1960s for the younger adults, and generalizes at later ages between the 1970s and the 1980s. The pattern observed for adult females is quite different. Their mortality risk is similar to that of males at the beginning of the period, but their mortality decline begins much earlier and gives them an increasing advantage over men. Until the 1970s, mortality rates among adult males hardly change, especially at ages above sixty. On the contrary, the decline of adult female mortality shows no sign of slowing down. From the mid1970s, mortality rates decline for both genders even at older ages, although at a slower pace for men than for women.

Figure 4.3 shows the behavior of the ratio between male and female mortality, respectively, over time for selected ages and by cohort. Over time, the two genders diverge to such an extent that the mortality risk of a sixtyyear-old Italian woman today is only about half the risk of a male of the same age. Differences in lifestyle and work environment help explain this huge difference. Traffic accidents among the young, lung cancer and heart attacks for adults, and cardiovascular diseases for the elderly are the main causes of the gender gap that grows over most of the 1900s. These causes are clearly linked to risk factors identified with being male-speeding, smoking, working conditions, eating habits, and alcohol abuse. The figure
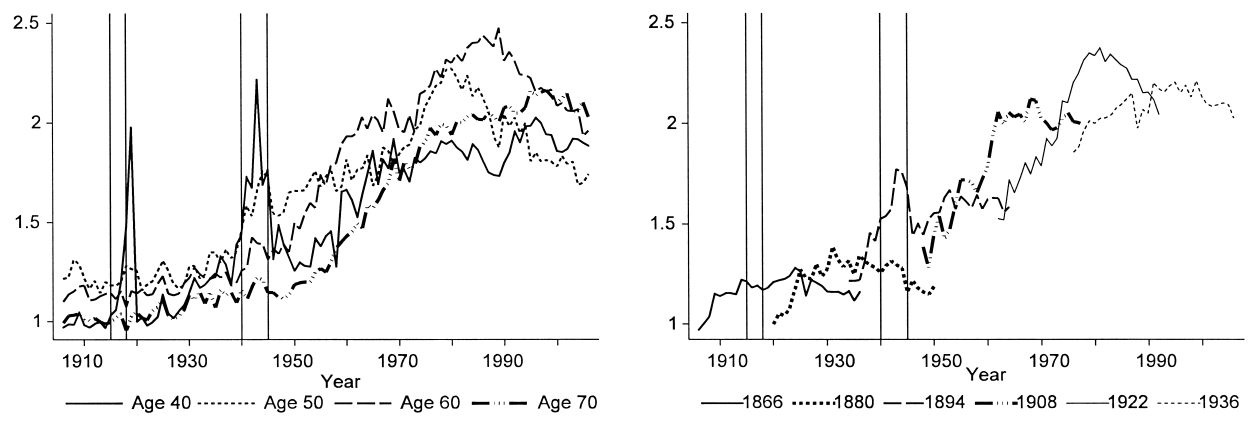

Fig. 4.3 Relative male mortality, over time (left) and by birth cohort (right) 
suggests a reversal of the trend in recent years with the gap narrowing, albeit slowly.

\section{Regional Differences}

Italy is one case where going beyond the aggregate trends is important because of the considerable degree of heterogeneity across regions. In this section we briefly consider the evidence obtained from the life tables produced by ISTAT for each single year from 1974 to 2006, and broken down by age, gender, and region of residence.

At the beginning of the 1900s, adult and elderly male mortality in Southern Italy was on average much lower than in the North, and especially much lower than in the Alpine areas, while differences in female mortality were smaller (Caselli et al. 2003). The gap in adult male mortality between the North and the South grew over time, reaching a maximum in the early 1970s. Taking life expectancy at age sixty as reference, a sixty-year-old man from Lombardy could expect to live about three years less than someone of the same age from Sardinia or Calabria. The life tables for the early 1990s show that, for men, the geographical features of mortality remain qualitatively unchanged but the size of regional differences is considerably narrower, largely due to the gains made in the North compared to the South. The life tables for the early 2000s show that, with the exception of Campania, regional convergence in male mortality has essentially being reached. The southern region of Campania is an exception because it continues to exhibit relatively high levels of mortality, a disadvantage that is actually slowly increasing in relative terms compared to the other regions. The geographical features of mortality in the early 2000s are the opposite for older women, with the Southern regions now exhibiting higher mortality rates than the North or the Center, although regional differences are smaller for females than for males. Once again, Campania tops the list, with sixty-year-old women having a life expectancy that is two years shorter than the Italian average, followed by Sicily, Basilicata, and Calabria.

Figure 4.4 summarizes these trends by showing the time profile of female and male mortality between 1974 and 2006 for the three macro regions of the country, namely the North, the Center, and the South and Islands. For both men and women, the largest gains in survival during the last thirty years have been made in the Northern regions. The different behavior of mortality in the North and the South between the 1970s and the 1990s is largely explained by the different evolution of mortality for cardiovascular diseases. The decline of this specific cause of death, which is the real protagonist of the positive trend of the last thirty years, has been especially strong in the Northern regions, partly because of the better quality of the health services and partly because of the success of prevention campaigns in changing eating habits and lifestyles at the individual level, which is of fundamental importance in order to control the risk factors that cause these kinds of diseases. 

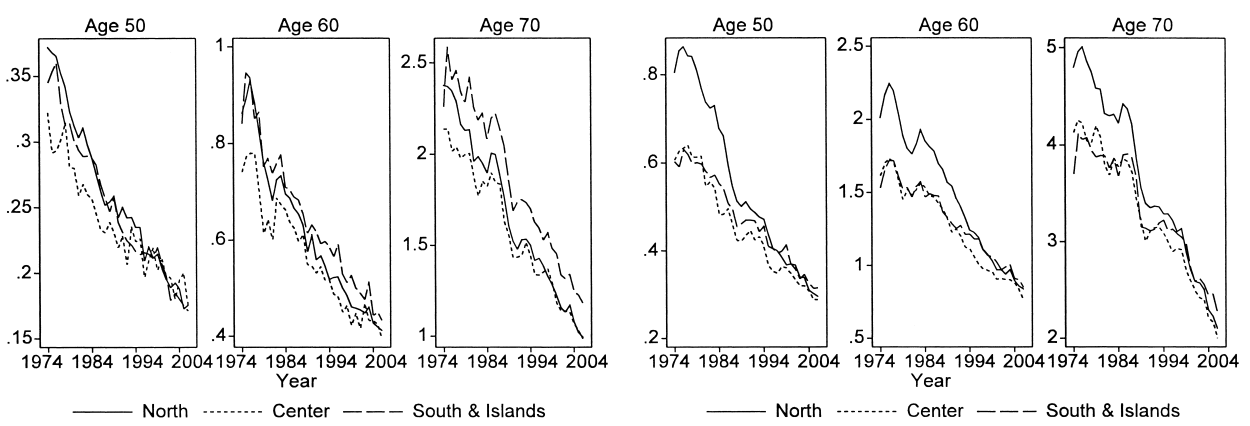

Fig. 4.4 Mortality rates over time by region (women left, men right)

\section{Recent Trends among the Elderly}

A noticeable feature of recent years is the acceleration of the trend toward falling mortality among people over age sixty. In terms of life expectancy at age sixty, males gained 1.5 life years between 1906 and 1956, and 6.1 life years between 1956 and 2006, while women gained 3.3 life years between 1906 and 1956, and 8.3 life years between 1956 and 2006, giving them an advantage of nearly 4.2 life years over men of the same age (figure 4.5).

Perhaps more striking is the sharp decline in mortality of older people (aged eighty and above) over the last fifty years. In terms of life expectancy at age eighty, men gained only 0.23 life years between 1906 and 1956 but a full three life years between 1956 and 2006, while women gained only 0.5 life years between 1906 and 1956 but 4.4 life years between 1956 and 2006, giving them an advantage of nearly two life years over men of the same age. Figure 4.5 shows recent trends in mortality for three age-groups that are of interest in this chapter. For both genders there is a steady decline in the mortality rate since the 1970s, but men start at a much higher level (almost thirty out of 1,000 men aged sixty-five in 1970) and their decline is more substantial. Since women have already gained longevity in the past decades, women in the younger age-group of fifty-five show a negligible decline in the mortality rate.

Mortality is increasingly concentrated among the oldest old. If we consider the Italian women, most of the deaths now occur after age seventy and, in particular, after age eighty. According to some demographers, we are witnessing the opening up of new frontiers in elderly survival. It is widely held that primary prevention, closely linked to the large investments in education and, more generally, in the human capital of the new cohorts, will play a crucial role in increased longevity. Opponents of this optimistic view stress instead the negative effects of pollution and modern lifestyles, and also argue that lack of selection at early ages may increase frailty and compromise health during old age.

To further appreciate the recent gains in longevity, figure 4.6 presents the ages of equal mortality probability with respect to a reference age for 

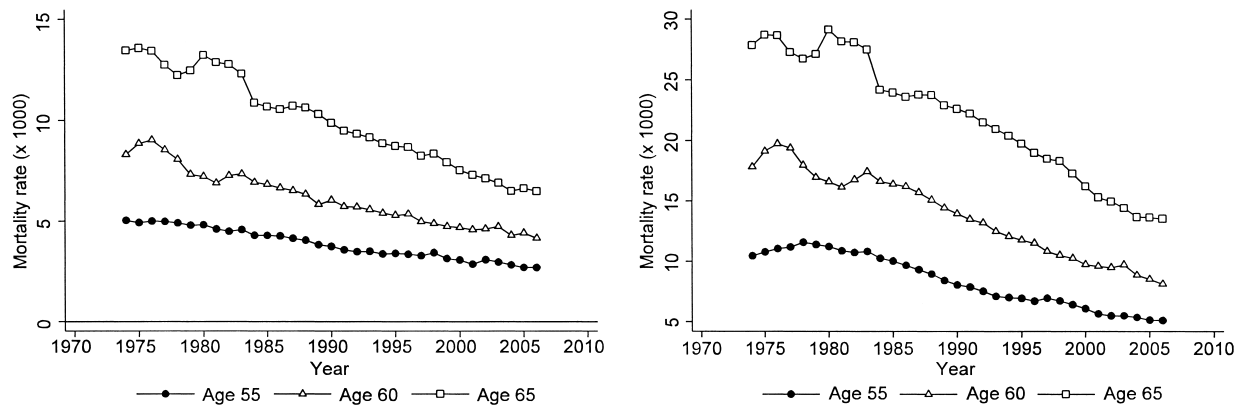

Fig. 4.5 Mortality rates at different ages (women left, men right)
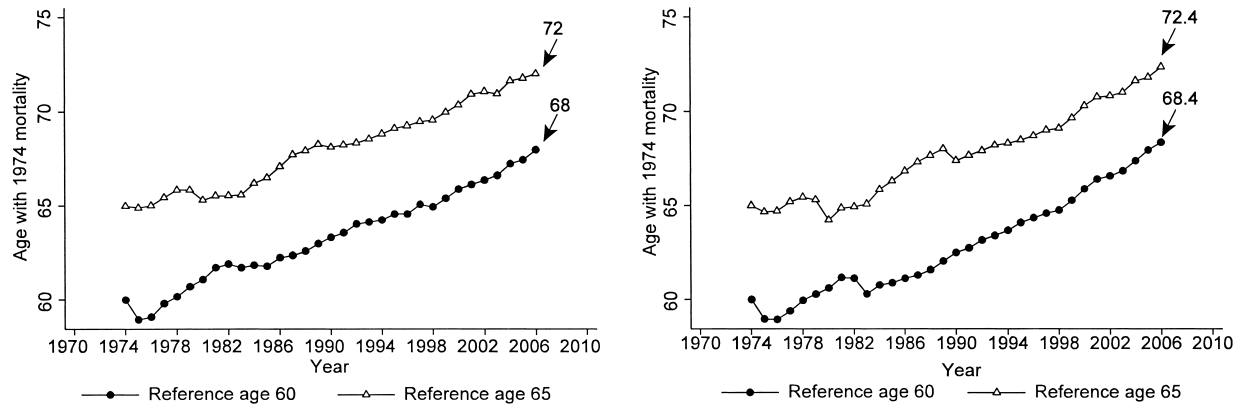

Fig. 4.6 Ages of equal mortality probability (women left, men right)

females and males separately. In 2006 a woman aged sixty-eight has the same mortality probability as a woman aged sixty in 1974 (and a woman aged seventy-two has the same as a woman aged sixty-five in 1974). For men the gains in survival are even more important in the recent years (a man aged 68.4 in 2006 has the same mortality probability of a man aged sixty in 1974). Figure 4.7 provides the same evidence in a more direct way by showing two-year mortality rates by age and gender. At a mortality rate of 5 percent, both men and women experienced gains between 1974 and 2006 of six years (from seventy-two to seventy-eight for men and from seventy-six to eighty-two for women).

\subsubsection{Mortality by Cause of Death}

Unfortunately, Italy does not have any readily available measure of health status (such as self-reported measures of health) over a sufficiently long period. The only evidence available for a sufficient time-span is mortality rates by causes of death (figure 4.8).

The mortality decline observed throughout the 1900s is largely driven by the steady decline of mortality due to cardiovascular diseases. This appears 


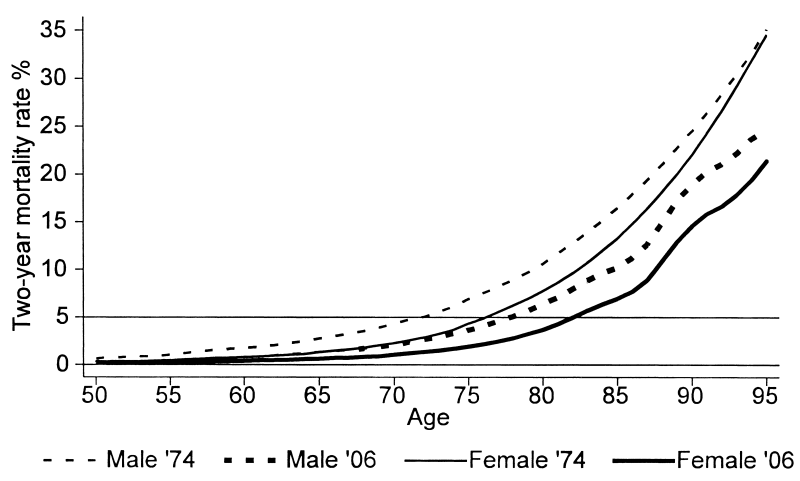

Fig. 4.7 Two-year mortality rates by age and sex

to be true for both genders. Mortality by cancer is also falling or remaining constant, especially in the sixty to seventy-nine age range, particularly for males. During the 1990s, the reduction of the gap in mortality between males and females is especially noticeable for the cohorts born after World War II, and reflects the sharper reduction of cardiovascular diseases and cancer among males (Caselli and Egidi 2010). This trend is likely to continue in the future. Caselli and Egidi (2010) point out that the better performance of females in terms of survival probabilities masks their relative disadvantage in terms of health and functional limitations, a disadvantage that grows rapidly between sixty and seventy-nine years of age and becomes especially important after eighty years of age. They also argue that this contradiction between the longer life expectancy of females and their worse health is likely to remain in the future.

An important issue is the age when functional limitations first appear. Caselli and Egidi (2010) show that this age has been increasing steadily over time, especially for women. Thus, the large gains in life expectancy observed during the last few decades have been accompanied by substantial gains in the quality of life at older ages. Despite this progress, the mere increase in the size of the elderly population implies a dramatic increase in the number of people affected by functional limitations. According to Caselli and Egidi (2010), the number of people aged sixty and above with partially reduced functional abilities would reach eight million, of whom four million would be aged eighty and above.

\subsubsection{Labor Force Status and Health Conditions}

We now turn our attention to the relation between labor force status and health conditions. Figure 4.9 plots the age-profile of employment rates in Italy in three different years (1977, 1990, and 2003), separately for women and men. The figure makes use of the Modello di Analisi Regionale della Spesa Sociale (MARSS) data set, which provides comparable figures on 

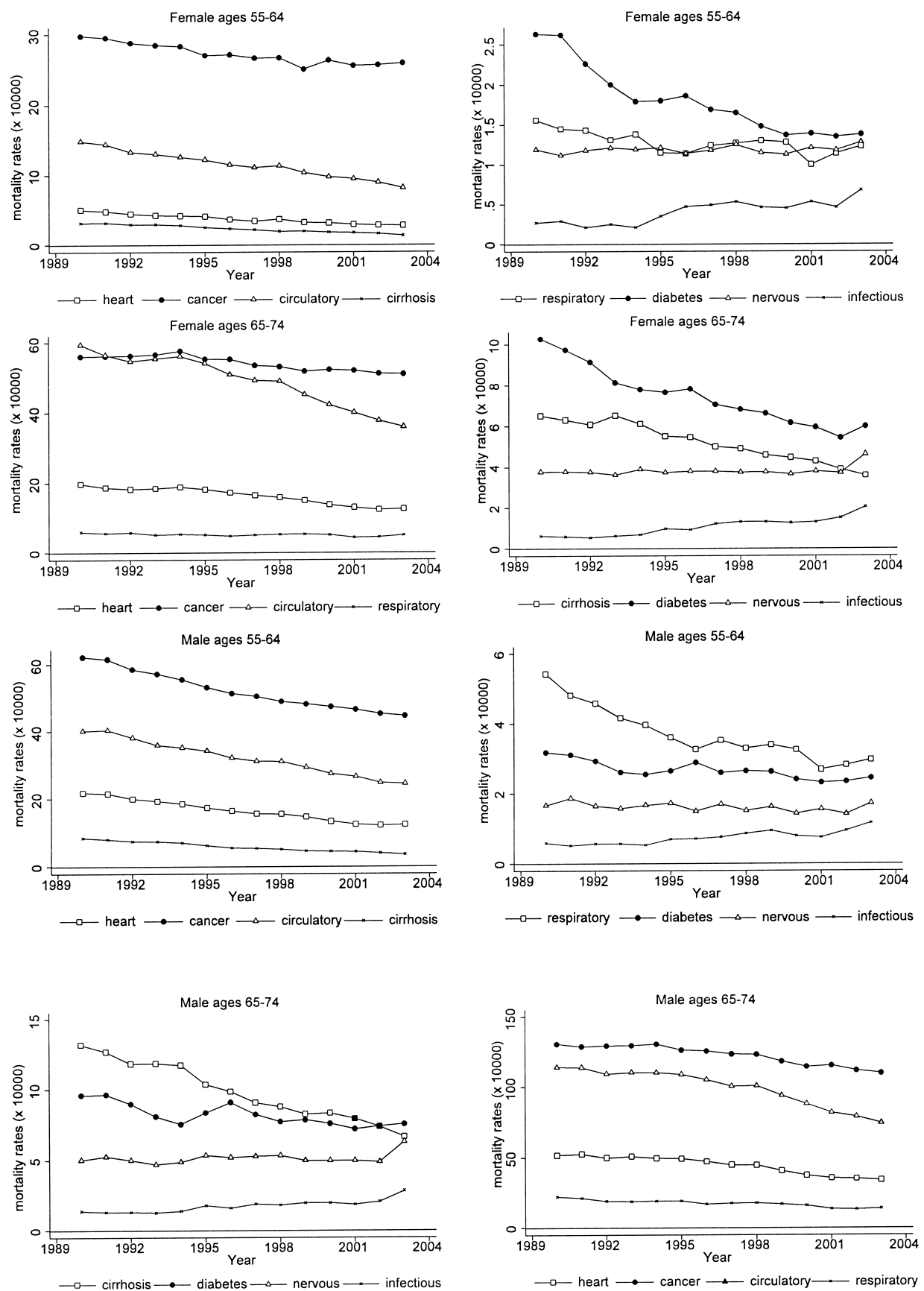

Fig. 4.8 Mortality rates by cause of death 

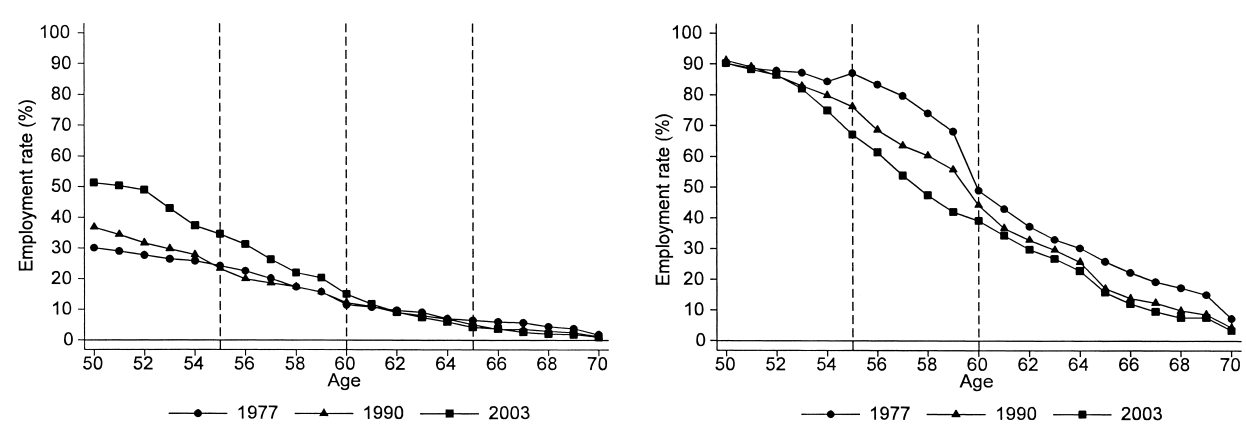

Fig. 4.9 Employment rates by age (women left, men right)

employment, unemployment, and nonemployment by age, gender, and region from 1977 to 2003 and has been constructed by ISTAT by putting together the cross-sectional information from the various waves of the labor force survey. The figure reveals several striking features of the Italian labor market. First, employment rates at older ages are much higher for men than for women: it is only in 2003 that the employment rate of women aged fifty and fifty-one reaches 50 percent, while for all other ages it is well below this percentage. Second, as widely documented elsewhere (Brugiavini and Peracchi 2004, 2007), after age fifty employment rates decline monotonically, with a sharp drop at age fifty-five and again at ages sixty and sixty-five. This is especially true for men: by age sixty, their employment rate has dropped from the value of 90 percent at age fifty to below 50 percent. Third, the 2003 profile of employment rates is entirely above the 1997 and 1990 profiles for women (i.e., there is an increasing trend in employment rates at all ages considered), but is entirely below for men (i.e., there is a declining trend in employment rates at all ages considered).

To see whether there is any link between these patterns and the health conditions of workers, we examine the relationship between employment rates and mortality rates in three different years $(1977,1990$, and 2003), separately for men and women (figure 4.10). For both genders, this relationship is negative, with higher mortality associated with lower employment rates, suggesting a possible link between falling employment rates and declining health status. Notice, however, that women exhibit a much lower attachment to the labor market than men, despite their higher longevity.

In fact, the negative relationship between employment rates and mortality is just spurious, being driven entirely by the age trend. This is shown clearly in figure 4.11 , which presents the scatter plot of employment rates and mortality rates at three different ages (fifty-five, sixty, and 65), separately for females and males. The scatter plots show that, over time, the relationship between employment and mortality rates is actually positive at all ages for men and for older women, while it is negative for younger women. This 

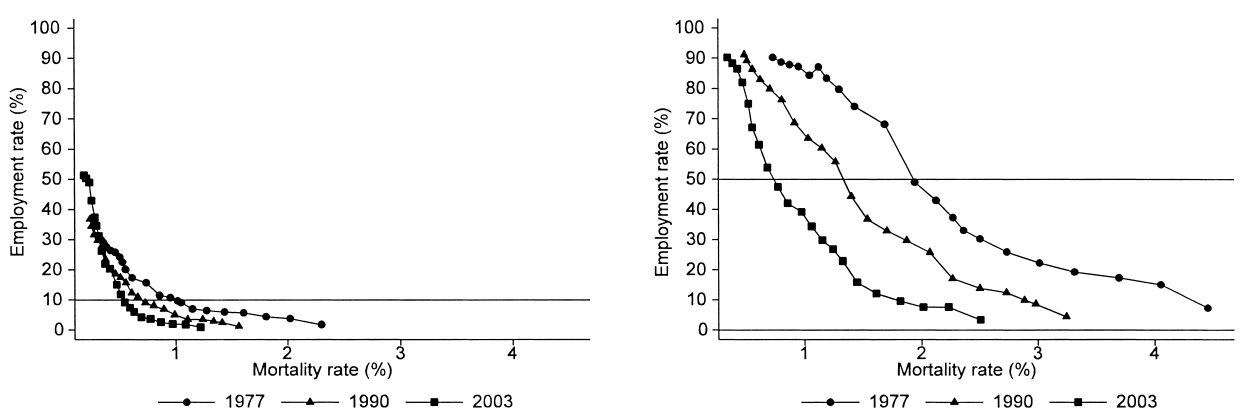

Fig. 4.10 Employment and mortality rates over time (women left, men right)
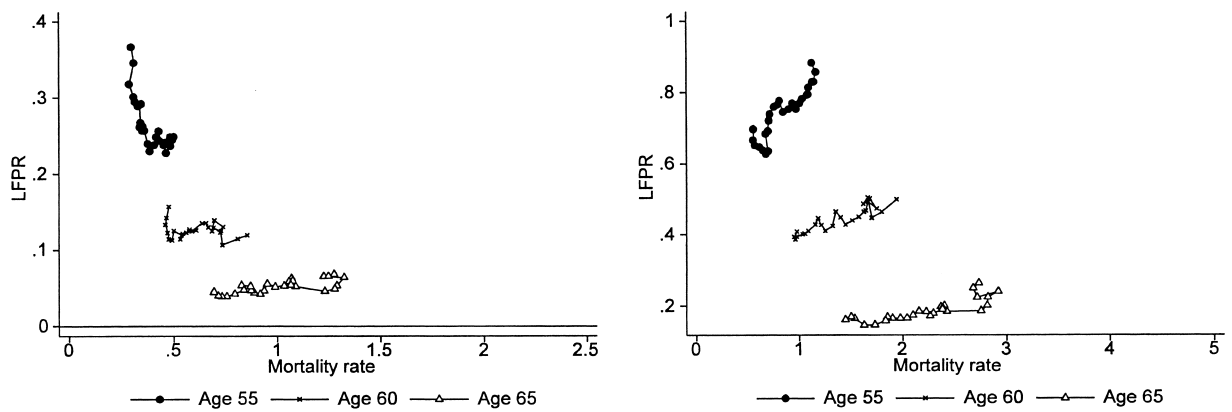

Fig. 4.11 Employment and mortality rates by age (women left, men right)

suggests that, at least for men and older women, one cannot associate the declining trend in employment rates to worse health conditions.

In order to relate this evidence to social security programs, we compare time trends in three dimensions: (a) mortality rates, based on the ISTAT data; (b) employment rates, based on the MARSS data; and (c) pension recipiency rates (the fraction of people of a given age who receive DI or early retirement benefits), based on the INPS sample. The evidence, presented in Figures 4.12 and 4.13, should be interpreted with care, as the first two dimensions are based on nationally representative data, while the latter is a sample from the administrative archives of the main Italian institution administering public pensions. Hence, for the INPS sample, the reference population differs from the general population. Also notice that, in the INPS data, people with an early retirement pension are registered as early retirees even past the normal retirement age. To allow for gender comparisons, graphs for women and men are presented on the same scales, the left-scale for employment rates and pension recipiency rates, and the right-scale for mortality rates.

The evidence from figures 4.12 and 4.13 is in line with our previous findings: mortality rates have declined steadily over time, particularly for the 
Benefits recipiency at age 55-59 and mortality at age 55

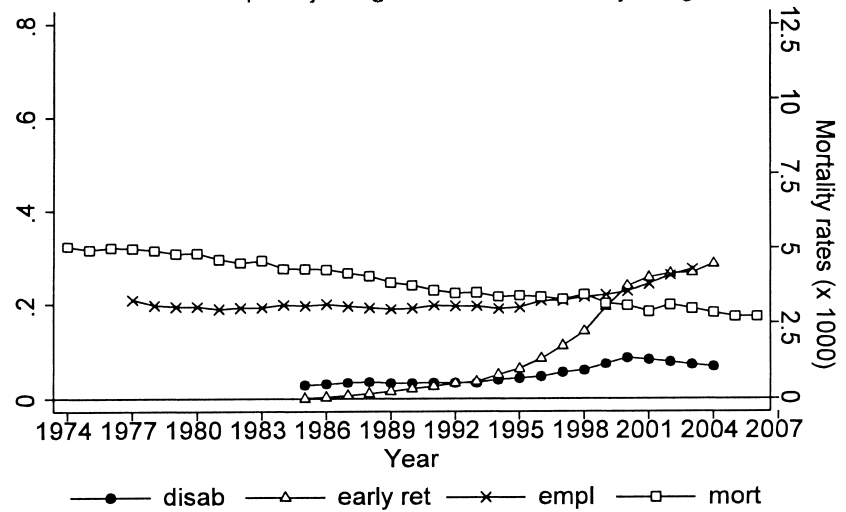

Benefits recipiency at age $60-64$ and mortality at age 60

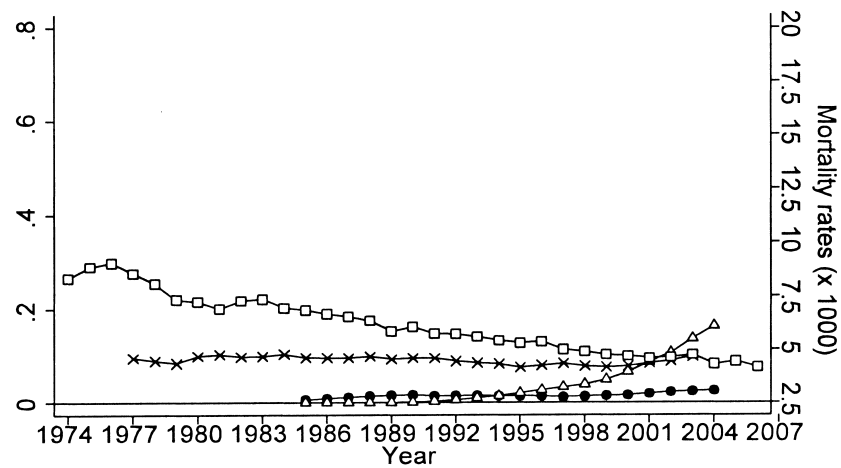

$\longrightarrow$ disab $\longrightarrow$ early ret $\longrightarrow$ empl $\longrightarrow$ mort

Benefits recipiency at age 65-69 and mortality at age 65

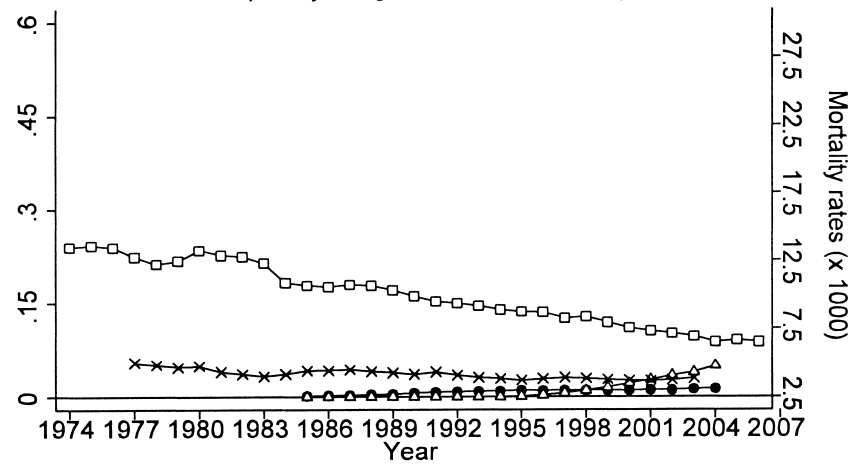

$\longrightarrow$ disab $\longrightarrow$ early ret $\longrightarrow$ empl $\longrightarrow$ mort

Fig. 4.12 Employment rates, mortality rates, and pension recipiency rates over time (women) 
Benefits recipiency at age 55-59 and mortality at age 55

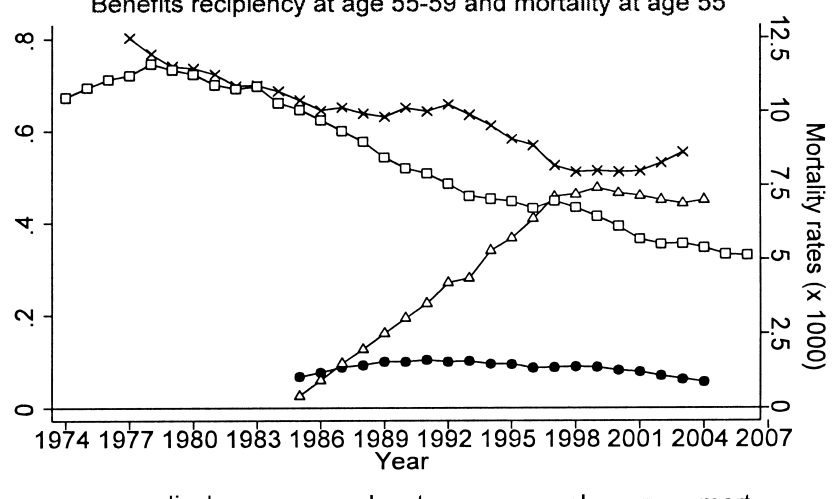

Benefits recipiency at age 60-64 and mortality at age 60

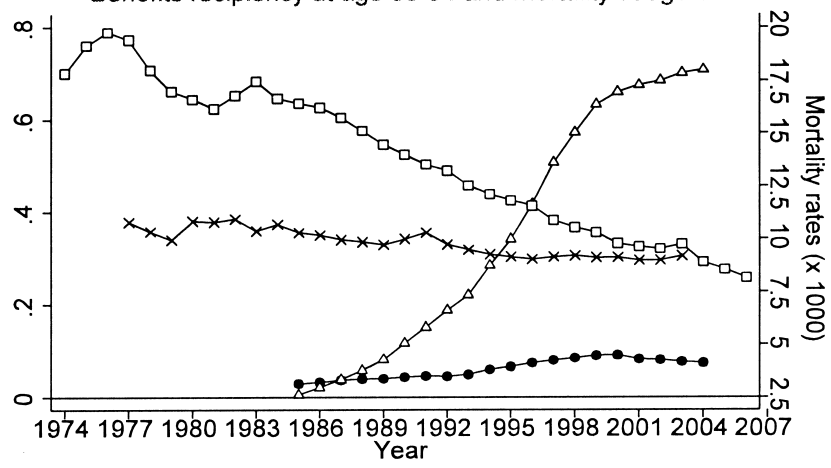

$\longrightarrow$ disab $\longrightarrow$ early ret $\longrightarrow$ empl $\longrightarrow$ mort

Benefits recipiency at age 65-69 and mortality at age 65

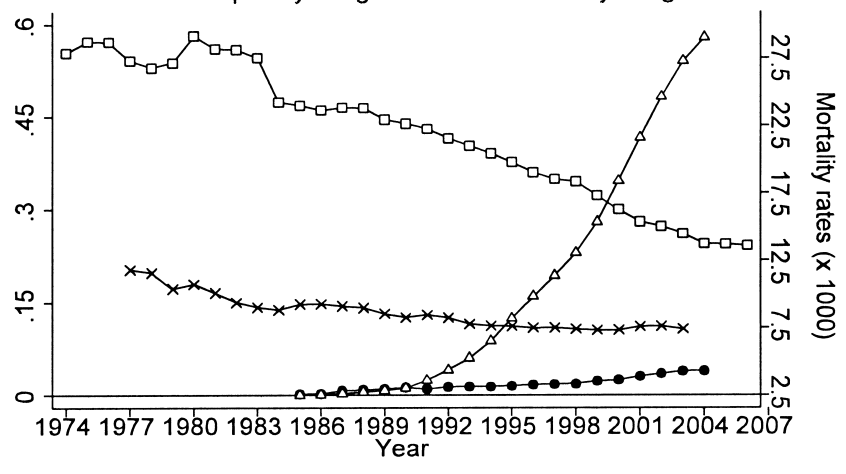

Fig. 4.13 Employment rates, mortality rates, and pension recipiency rates over time (men) 
age-groups fifty-five to fifty-nine and sixty to sixty-four, employment rates have also declined (except for the younger women), while recipiency rates of DI benefits have remained stable or increased only slightly. In contrast, recipiency rates of early retirement pensions have increased significantly over time for both men and women, at all ages. This prima facie evidence suggests that, while health conditions have improved over time (as measured by mortality), employment of the elderly has fallen, the typical exit route from the labor force being early retirement. In the next section we look in more detail at the relationship between labor force participation and participation to social security programs.

\subsection{Exit from the Labor Force and Program Reforms}

\subsubsection{Disability and Social Security Reforms versus LFP and Pathways to Retirement}

The evidence discussed so far poses the important question of how the length of the working lives of Italians has adapted to the increases in longevity during the last decades. Brugiavini and Peracchi (2010) show that, not unlike other countries, the working life of Italian workers has been shrinking for some time after World War II.

Figure 4.14 shows aggregate labor force participation rates based on the MARSS data. ${ }^{7}$ The time span is 1977 to 2003 and we distinguish between six age-groups (forty to forty-four, forty-five to forty-nine, fifty to fiftyfive, fifty-five to fifty-nine, sixty to sixty-four, and sixty-five to seventy). As discussed in previous contributions (Brugiavini and Peracchi 2010), aggregate labor force participation is increasing for the younger age-group (age forty to fifty), and constant or even declining for the older age-groups (sixty and above). However, there are important gender differences, as the upward trends are totally explained by female labor supply, especially for the younger cohorts. Focusing on the ages at risk of exit from the labor force (ages fifty-five and older), figure 4.15 shows that men have substantially reduced their participation over time, although a reversal of the trend can be observed after the Dini reform in 1995, especially for the fifty-five to fifty-nine age-group.

In order to document the effect of the different welfare provisions on labor supply and program participation at older ages, we again use the INPS sample. These data contain two types of information. The first is the stock information on the number of workers paying social security contributions at the end of each year, along with the number of beneficiaries by type of benefit (old-age, early retirement, DI, or survivor pension). ${ }^{8}$ The second is

7. See footnote 9.

8. These beneficiaries are mostly widows who, although previously or currently working, have their husband's survivor pensions as the main source of income. 


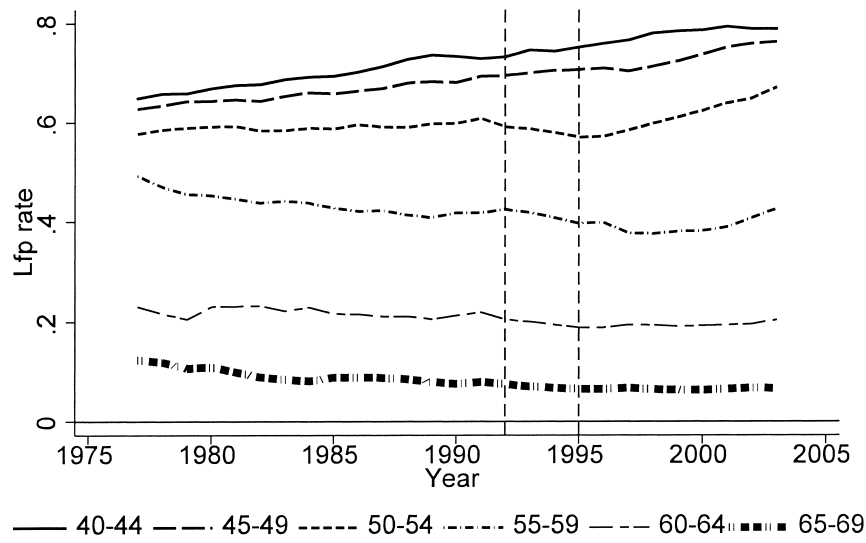

Fig. 4.14 Aggregate labor force participation rates by age-group
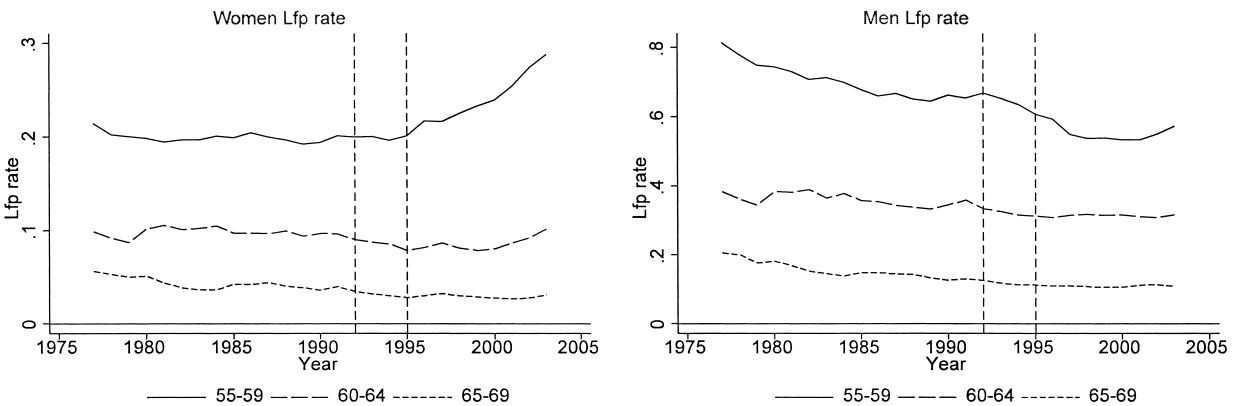

Fig. 4.15 Labor force participation rate by age-group and gender

the flow of information on the number of new pension awards each year. We focus on the period from 1990 to 2004.

Figure 4.16 shows the changes over time in the composition of the INPS sample by pension recipiency status for four age-groups (fifty to fifty-four, fifty-five to fifty-nine, sixty to sixty-four, and sixty-five to sixty-nine). In constructing the graphs, we drop benefit recipients who could not be linked with their earnings history (for example, former public-sector employees or widows who had no earnings ever in their lives but currently collect survivor benefits). We also drop people who receive either "pre-pensions" ( prepensionamenti), which are a form of early retirement available to employees of selected firms in specific industries undergoing severe crisis, or benefits that are not work-related, such as income maintenance for the elderly ( pensione sociale). ${ }^{9}$ There are two main reasons for our sample selection criteria.

9. Pre-pensions will be discussed in section 4.4.2 when looking at trends in newly awarded benefits. 

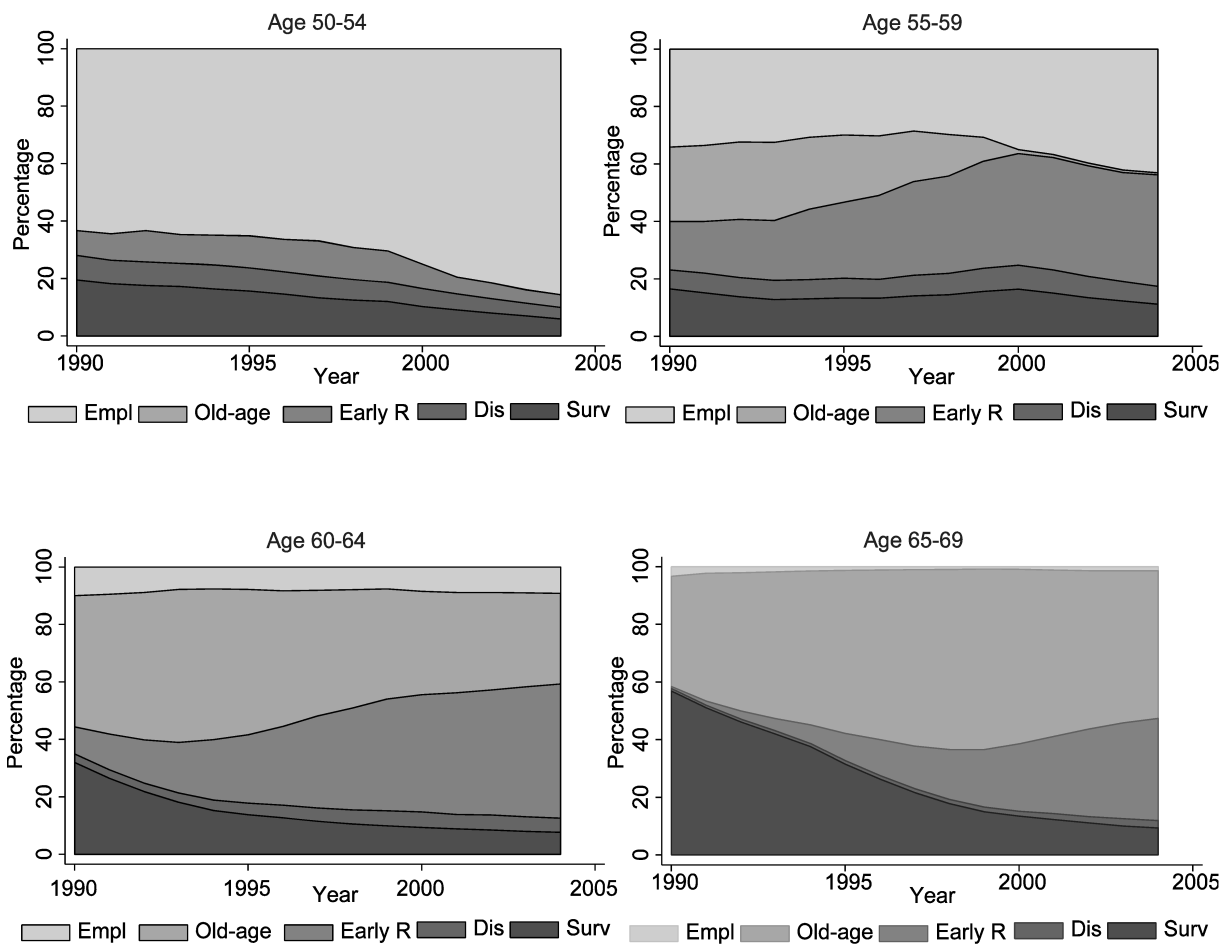

Fig. 4.16 Program participation rates over time (both genders)

First, we are interested in the transition from work to other nonemployment states and want to focus on former (or current) workers only. Second, it is possible for people to work and collect some benefit (for example, disability benefit), or to collect more than one benefit at the same time; in these cases we assign individuals to one category or the other on the basis of an income criterion (e.g., individuals are disability-claimants if the main source of income is the disability pension). Hence we need to have information on earnings as well as benefits for each individual.

At younger ages (fifty to fifty-four), recipients of either early retirement or survivor benefits represent a significant percentage of the sample, but this percentage has been falling since the year 2000, partly in response to the pension reforms and partly because of cohort effects. Program participation rates at ages fifty-five to fifty-nine and sixty to sixty-four are very interesting: for this age-group, early retirement is becoming an increasingly important exit route (at least until about the year 2000), replacing the old-age exit route. This is explained by the tighter entry-age conditions gradually applied after the Amato (1992) reform, which are particularly biting for women (see table 4.1 in section 4.2). For the older age-group (sixty-five to sixty-nine) the pattern is similar but old-age pensions remain the most important exit route. 
The DI pensions are not particularly relevant and show no clear pattern over the period considered.

\subsubsection{Effects of Pension Reforms on Labor Force Participation}

Because the timing and content of the Italian reforms of the 1990s were hardly anticipated (this is especially true for the Amato reform), these pension reforms may be regarded as natural experiments that provide the exogenous variation that is needed in order to evaluate the effects of specific policy changes on labor force participation. By focusing the attention on the 1992 and 1995 pension reforms, we compare labor market participation before and after the reforms for different cohorts. The data set that we use is again MARSS. Results are presented in table 4.2 in the form of exit rates (in percentages), which are obtained by taking the between-years rate of change in the labor force participation for a given cohort and gender. The first column (rate 1989 to 1986) shows the exit rates before the main reforms of 1992 and 1995, while the last column shows the same exit rates well after the reforms. ${ }^{10}$

While we cannot draw sharp conclusions on the basis of these results, we can distinguish two significant effects of the two main pension reforms of the 1990s, the Amato (1992) and the Dini (1995) reforms. The first, which we call an "announcement effect," consists of a clear "run to retirement." We observe this effect immediately after the pension reforms were announced and approved by the Parliament. Since the reforms were characterized by more restrictive eligibility conditions, many workers who satisfied the eligibility requirement for retirement in 1992 and 1995 decided to retire as soon as possible because of the fear of being trapped in their jobs. Such an effect is visible for all the cohorts that were between fifty-five and sixty-three years of age in 1992 to 1995, both men and women. Table 4.2 documents that the exit rate of men in the cohort born between 1932 and 1934 (aged fiftyeight to sixty in 1992 and sixty-one to sixty-three in 1995) was 45.3 percent between 1992 and 1995, that is almost 7 percent higher than the exit rate of the cohort 1929 to 1931 when reaching the same age (between 1989 and 1992). Also, between 1992 and 1995 and between 1995 and 1998 the exit rate of men aged fifty-eight to sixty (cohorts 1935 to 1937 and 1938 to 1940) was 29.0 percent and 30.2 percent respectively, versus 21.8 percent of the cohort 1932 to 1934 when of the same age. Similar effects are also observed for women. For example, the exit rate of women aged fifty-eight to sixty in 1995 (fifty-five to fifty-seven in 1992) is 7 percent higher than for women of the same age in 1992.

The second effect is a direct "mechanical effect" of the change in the rules

10. There have been some minor changes in 1997 and in the following years that have tightened eligibility conditions for early retirement. However, while the 1992 reform (and to some extent also the 1995 reform) was unexpected, these changes were by and large predictable. 
Table 4.2

Exit rates by cohorts and gender (percent)

\begin{tabular}{lcccccc}
\hline & Cohort & $\begin{array}{c}\text { Exit rate } \\
89-86\end{array}$ & $\begin{array}{c}\text { Exit rate } \\
92-89\end{array}$ & $\begin{array}{c}\text { Exit rate } \\
95-92\end{array}$ & $\begin{array}{c}\text { Exit rate } \\
98-95\end{array}$ & $\begin{array}{c}\text { Exit rate } \\
01-98\end{array}$ \\
\hline Men & $26-28$ & 40.59 & $\underline{41.23}$ & 53.64 & 55.30 & \\
Men & $29-31$ & $\mathbf{2 4 . 7 8}$ & 37.82 & $\underline{47.31}$ & 51.47 & 59.17 \\
Men & $32-34$ & 20.24 & $\mathbf{2 1 . 8 5}$ & 45.30 & $\underline{41.77}$ & 47.78 \\
Men & $35-37$ & $\mathbf{9 . 1 0}$ & 15.46 & $\mathbf{2 9 . 0 1}$ & 37.87 & $\underline{44.48}$ \\
Men & $38-40$ & 1.81 & $\mathbf{1 1 . 7 9}$ & 20.67 & $\mathbf{3 0 . 2 3}$ & 31.87 \\
Men & $41-43$ & -0.21 & 5.63 & $\mathbf{1 6 . 0 8}$ & 23.19 & $\mathbf{2 5 . 8 9}$ \\
Men & $44-46$ & -0.39 & 1.72 & 8.83 & $\mathbf{1 3 . 1 6}$ & 22.12 \\
Women & $26-28$ & 41.82 & $\underline{45.49}$ & 56.68 & 43.41 & \\
Women & $29-31$ & $\mathbf{3 2 . 9 2}$ & 42.51 & $\underline{47.03}$ & 51.90 & 47.20 \\
Women & $32-34$ & 29.79 & $\mathbf{2 8 . 3 3}$ & 52.39 & $\underline{35.83}$ & 52.06 \\
Women & $35-37$ & $\mathbf{1 3 . 0 9}$ & 27.25 & $\mathbf{3 5 . 7 1}$ & 45.20 & $\underline{47.59}$ \\
Women & $38-40$ & 4.49 & $\mathbf{1 3 . 2 4}$ & 30.24 & $\mathbf{3 2 . 7 1}$ & 47.12 \\
Women & $41-43$ & 2.50 & 5.30 & $\mathbf{1 5 . 9 9}$ & 21.29 & $\mathbf{3 1 . 6 3}$ \\
Women & $44-46$ & -4.70 & 6.41 & 6.51 & $\mathbf{1 4 . 0 0}$ & 20.06 \\
\hline
\end{tabular}

Source: The MARSS data on labor force, ISTAT.

Notes: The exit rate is obtained, for example, as (lfpr86-lfpr89)/lfpr86, where lfpr86 is the labor force participation rate in 1986. Bold grey characters: exit rates between age-groups 49-51 and 52-54. Grey characters: exit rates between age-groups 52-54 and 55-57. Bold characters: exit rates between age-groups 55-57 and 58-60. Italic characters: exit rates between agegroups 58-60 and 61-63. Underlined characters: exit rates between age-groups 61-63 and 64-66.

that forces workers to delay retirement. This effect has a smaller order of magnitude if compared with the announcement effect, and it also appears more diluted on a longer period of time over the years that follow the implementation of the reforms. The exit rates fall after 1996 for the younger age-groups and increase for the older ones. We can see that for men aged sixty-one to sixty-three the exit rate decreases in 1998 from 45.3 percent to 37.87 percent and further to 31.87 percent in 2001. A similar pattern is observed for men in the age-group fifty-eight to sixty and for women in the age-groups fifty-eight to sixty and fifty-five to fifty-seven. Basically what one can see in table 4.2 is that a decreasing number of individuals in these groups (cohorts) satisfy the new, more restrictive eligibility conditions for retirement after the year 1996. This interpretation is also supported by the increased exit rates of men aged sixty-four to sixty-six and of women aged sixty-one to sixty-three after 1998.

One has to be cautious in drawing a final conclusion on the effects of these pension reforms on labor market participation as, at the same time, other underlying trends could partly interact with our natural experiment, especially in the case of women. Further, our aggregate data do not properly account for the variety of possible exit routes that individuals experience, which do not necessarily respond to the same incentives brought about by the reforms. 

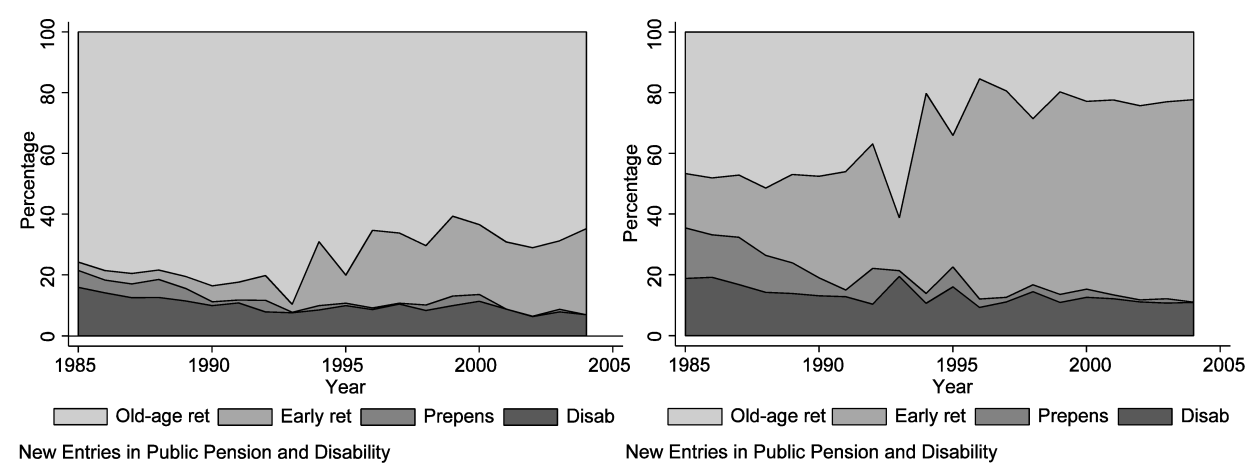

New Entries in Public Pension and Disability

Fig. 4.17 New entries by benefit type (women left, men right)

However, one general conclusion that we can draw from this very descriptive evidence is that pension reforms in Italy created huge disparities between cohorts, as also documented by the contributions of Attanasio and Brugiavini (2003) and Bottazzi, Jappelli, and Padula (2006).

Instead of focusing on changes in the stocks, figure 4.17 looks for evidence of the effects of the pension reforms of the 1990s by focusing on changes in the annual flows of newly awarded pensions by benefit type. We refer to these flows as "new entries" into the pool of pensioners. The graph uses the counts of individuals who, in each year, receive for the first time their pension from the three main INPS funds (namely FPLD and the Artisans and Traders Funds), obviously excluding from the sample those who never receive any benefit (which leaves us with approximately 145,000 individuals). The percentages are based on the date when the person received her or his first pension payment, which is the date at which the individual is recorded as entering the archive. The graph describes the routes of entry into the public pension system, but does not allow us to keep track of subsequent changes from one type of benefit to another. We observe that before 1993, that is, before the Amato reform, the prevailing channel for entering the welfare system was old-age retirement. After this date, old-age retirement shows decreasing percentages while early retirement increases until 1999, when the two exit routes reach some sort of steady state.

Figure 4.17 looks at men and women separately. In the case of men, oldage pensions after the reforms represent only about 22 percent of the total versus about 65 percent of entries through early retirement pensions. It is also striking to see a spike of early retirement entries in 1993, just after the Amato reform, followed by a dip in 1994 and again a spike in 1995, the year of the Dini reform. In our data we can also distinguish a particular type of early retirement, called pre-pension, available only to the employees of selected firms in specific industries undergoing severe crisis. This particular exit route, which was very popular in the 1980s, survived through the 1990s 
but practically disappeared after the year 2001, when it was replaced by early retirement pensions. Finally, DI pensions are steadily declining over time, from a starting value of approximately 20 percent in 1985 to about 10 percent in 2004. This is because the strict entry requirements introduced in 1984 ended up being quite effective. In 1993, when the percentage of new awards for early retirement diminishes abruptly, disability pensions show a spike together with old-age pensions.

Because the results presented in the previous figures may be affected by cohort effects, figures 4.18 and 4.19 look separately at two birth cohorts: people born in 1930 to 1939 and people born in 1940 to 1949. It is clear from the figures that the two cohorts followed very different routes in exiting the labor force. The earlier cohort exited predominantly through the

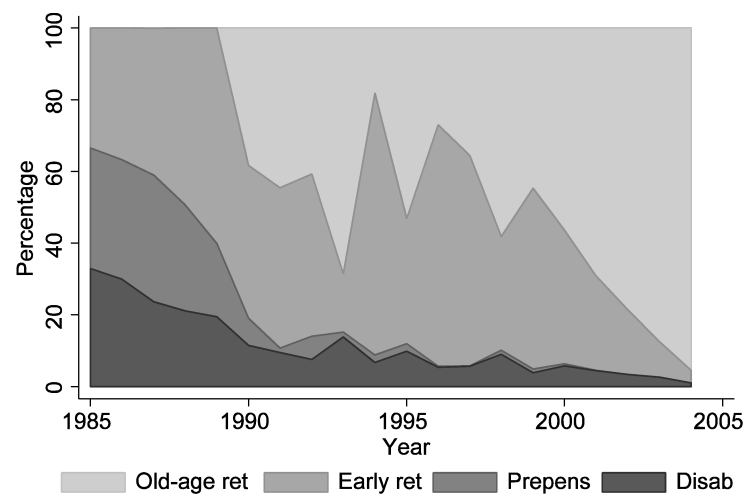

New Entries in Public Pension and Disability

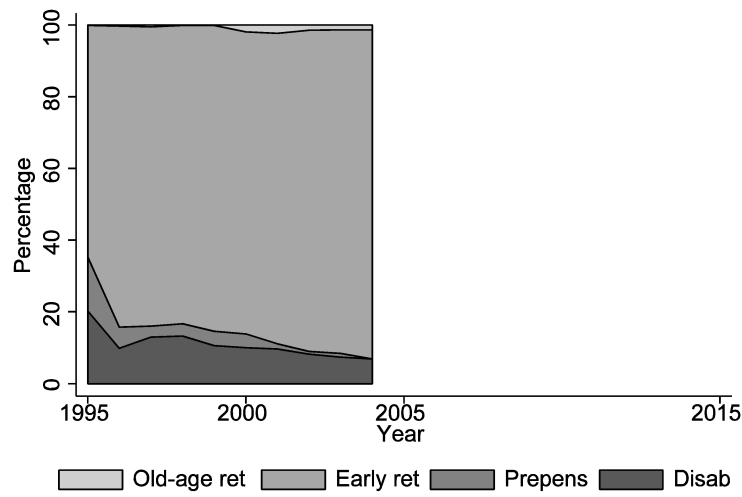

New Entries in Public Pension and Disability

Fig. 4.18 New entries by benefit type and birth cohort (men born 1930 to 1939 top, men born 1940 to 1949 bottom) 


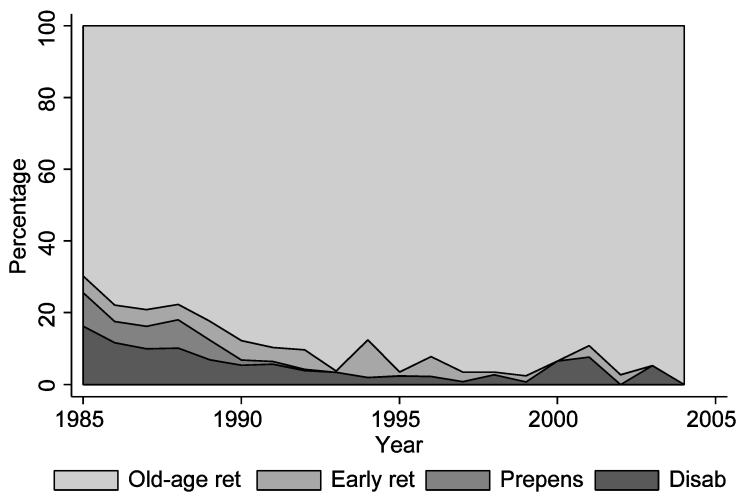

New Entries in Public Pension and Disability

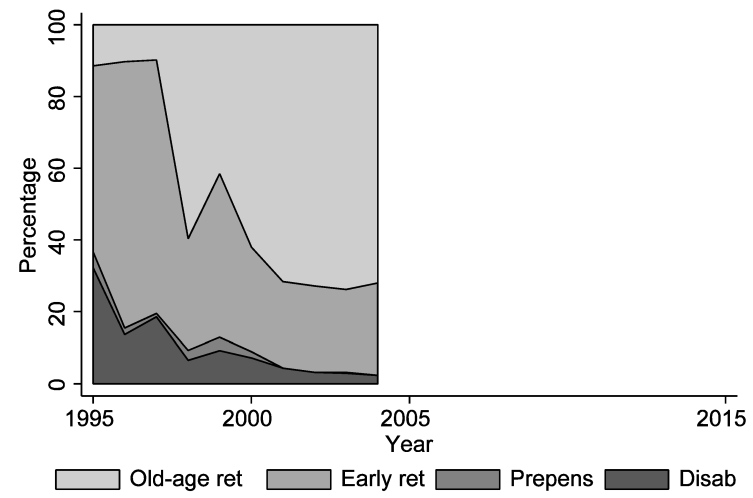

New Entries in Public Pension and Disability

Fig. 4.19 New entries by benefit type and birth cohort (women born 1930 to 1939 top, women born 1940 to 1949 bottom)

old-age pension route, although the DI pension route was also relevant. The later cohort, instead, exited almost entirely through the early pre-retirement route, especially in the case of men. This vividly illustrates the effect of the Amato and Dini reforms.

Notice that, although the trends for men and women are similar, the levels are quite different, as the early retirement route is much less important for women. This difference reflects three main factors. First, labor market participation for women in the two cohorts is very different. Second, the requirements for an old-age pension are different for men and women (age sixty for women, age sixty-five for men). Third, women hardly qualify for early retirement, as this benefit is awarded conditionally on a seniority requirement, that is, on the basis of the number of years of contributions. Because 
Italian female workers typically have short contributive histories (Boeri and Brugiavini 2009), this exit route is of secondary importance for them.

Another way of displaying the same information is to compute the rate of change in the newly awarded benefits. We do this in two ways: first with respect to the base year 1985, then year-by-year. While the first way is affected by the composition of the sample in the base year, the second way is strongly affected by some important changes taking place in the reform years, which cause huge variations in the denominator of the rate itself, making it very hard to properly interpret the hazards.

Figure 4.20 presents the percentage rates of change in entries in the public pension and disability insurance in the index-form, using the year 1985 as the base year. ${ }^{11}$ We used only the sample of individuals who were receiving their pension from the three main INPS funds (FPLD, Artisans, and Traders). We restrict the sample to birth-cohorts 1915 to 1950; that is, we consider individuals aged thirty-five to seventy in 1985, so that these individuals are potentially workers in the base year. The two dotted lines mark the years 1992 and 1995, which are the years of the two major pension reforms in Italy. We observe that entries in the pension system through prepensions diminish constantly starting in 1986 (except for the year 1992). On the other hand, entries through early retirement pensions exhibit a steady increase with two important peaks: one in 1992 and the other one in 1994. In addition, the old-age retirement route shows an almost constant path with a peak in 1992 followed by a slight decrease in 1993. It is important to note that a feature that is common to all three indexes is the changes in 1992 and in 1994. This is because the reforms had a strong announcement effect and Italy witnessed a run to retirement. Many workers who fulfilled the less restrictive retirement conditions in 1992 (or 1994) decided to retire immediately in order to avoid the risk of being trapped in their job, through whatever mode of retirement. At that point the easiest way out was through early retirement.

The same features characterize the paths of retirement for men, while for women the variability is larger, but this should be explained by the different participation of women to the labor market.

Unfortunately, due to the fact that the denominator changes abruptly from one year to the next, it is hard to interpret these figures, particularly when the absolute numbers are small, as in the case of pre-pensions. The important spikes are observed in 1992 and 1994 as expected.

11. The rates of change in retirement in the year $n$ with respect to 1985 , are:

$$
\frac{P_{n}-P_{1985}}{P_{1985}} \times 100
$$

where $P_{n}$ represents the number of retirees in year $n$ while $P_{1985}$ represents the number of retirees in the base year. 


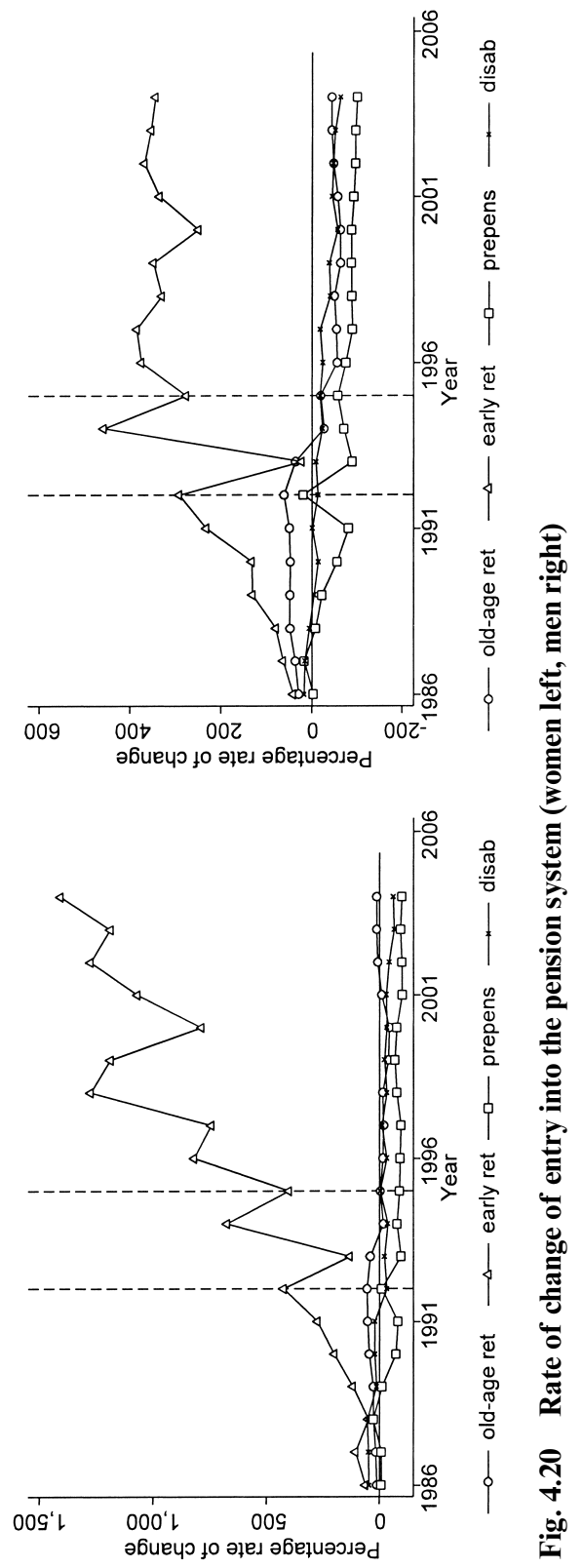




\subsubsection{Pathways into Retirement}

More compelling evidence on the effect of the different eligibility conditions applying to the different exit routes can be obtained by exploiting the panel dimension of the INPS sample. In order to follow the different pathways we focus on those individuals registered with INPS (i.e., paying contributions) who were working in 1985. Similar to the previous figures, we restrict the sample to individuals who were receiving some form of benefit from the three main INPS funds, and we add the condition that they were working in the year 1985 (approximately 78,000 individuals). Then, starting in 1985, we follow this sample during their working lives until exiting from the employment status and entering the social security archive.

Figure 4.21 shows the pathways as percentages of individuals who are in any of the mutually exclusive states: employees, early pensions, old-age pensions, pre-pensions, and so forth, by year and age-group. Figure 4.22
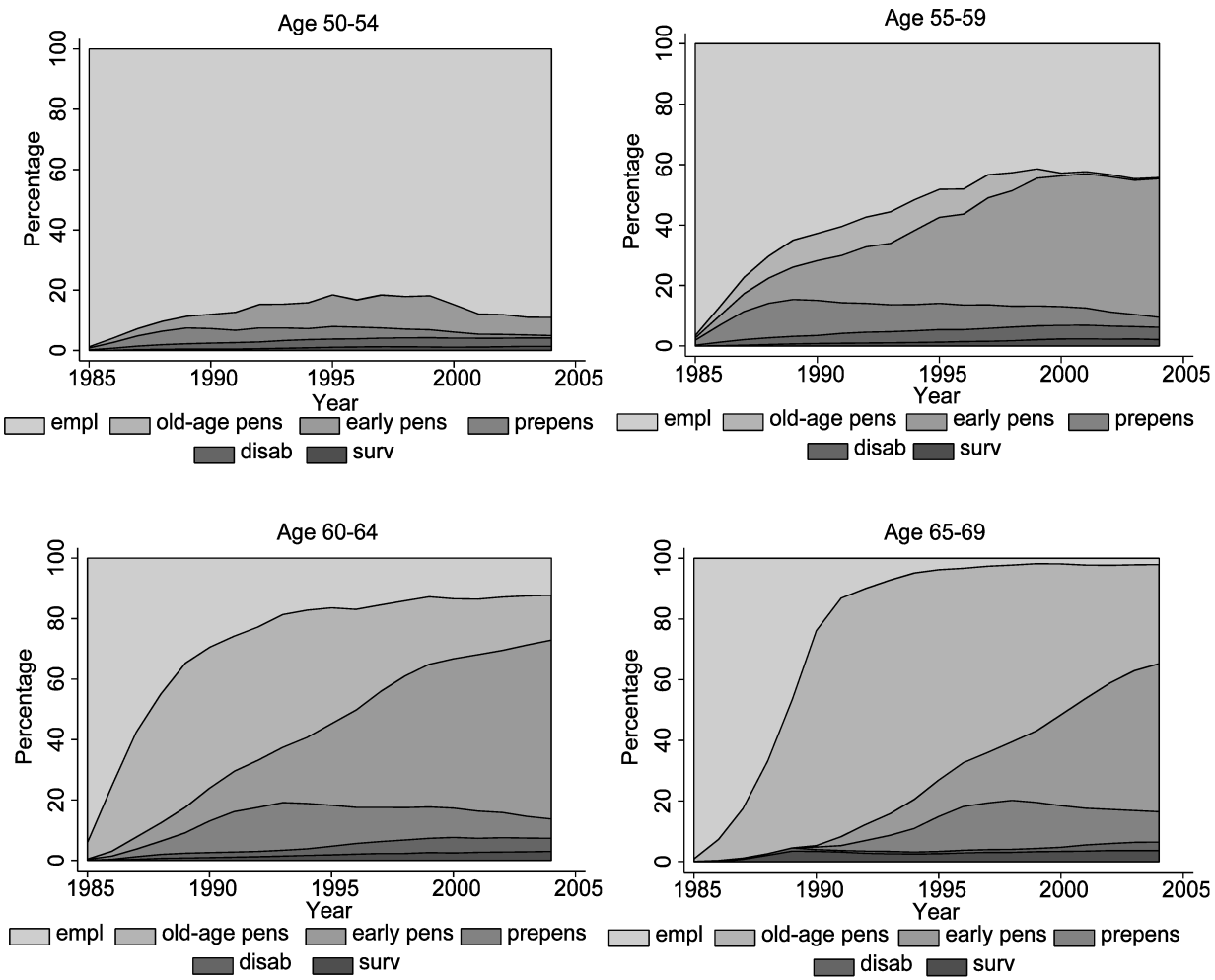

Fig. 4.21 Pathways into retirement: Participation to the different welfare programs for the panel sample of people working in $\mathbf{1 9 8 5}$, by age-group (both genders) 

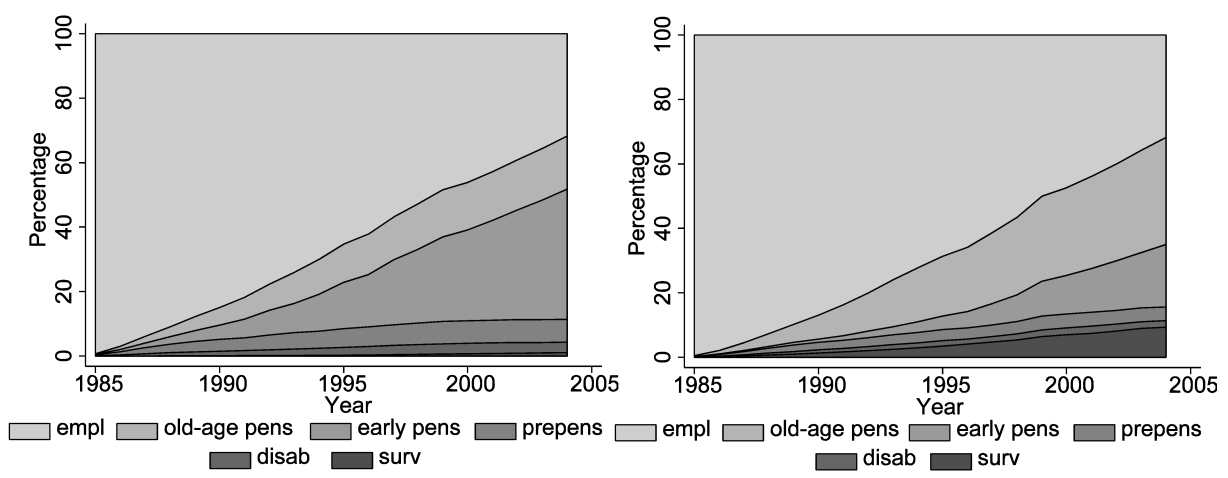

Fig. 4.22 Pathways into retirement: Participation to the different welfare programs for the panel sample (men left, women right)

compares pathways across genders. Since in some cases the same individual could be employed and receive a benefit (or could receive more than one benefit), we impute individuals to a labor market status on an income basis: the individual is defined as old-age retired if his or her old-age pension provides the highest income. Hence, in figures 4.21 and 4.22 we are not effectively looking at transitions from one state to another state, but simply showing participation in the different programs in a panel sample, conditional on being employed in 1985 .

It should be stressed that in our data an early retirement benefit is always recorded as such even if the beneficiary becomes older (aged sixty-five or above), while disability benefits are mostly automatically converted into oldage pensions when the disabled person reaches age sixty-five. This explains why, even at older ages, early retirement is a prevalent mode of being nonemployed. Once again we find that early retirement substitutes for old-age pensions as eligibility requirements for old-age pensions become more stringent. Disability pensions are not particularly relevant and they are also quite stable over time.

Proper transitions across states can be measured in the panel sample through transition matrices. Table 4.3 shows transition matrices for two groups of individuals distinguished by year of birth. Transitions are measured over a period of ten years. Table 4.3 clearly shows that in Italy the main exit route is directly via retirement (old-age pension or early retirement pension). Very few workers go into disability, and in fact, not many transit from work into retirement via disability.

\subsection{Trends in Labor Force Status and Program Participation}

To complete the analysis we provide historical data on individuals employed, unemployed, and not in the labor force. We make use of the 


\begin{tabular}{|c|c|c|c|c|c|c|}
\hline & Employment & $\begin{array}{c}\text { Job } \\
\text { pension }\end{array}$ & $\begin{array}{l}\text { Disability } \\
\text { pension }\end{array}$ & $\begin{array}{c}\text { Social } \\
\text { pension }\end{array}$ & $\begin{array}{l}\text { Non-contr. } \\
\text { pension }\end{array}$ & $\begin{array}{c}\text { Survivor } \\
\text { pension }\end{array}$ \\
\hline \multicolumn{7}{|c|}{ A. Cohorts 1931-1940 } \\
\hline \multicolumn{7}{|l|}{ Transitions 85-95 } \\
\hline Employment & 97.10 & 0.85 & 1.70 & 0.00 & 0.32 & 0.35 \\
\hline Job pension & 0.00 & 100.00 & 0.00 & 0.00 & 0.00 & 0.00 \\
\hline Disability pension & 0.00 & 0.00 & 100.00 & 0.00 & 0.00 & 0.00 \\
\hline Social pension & 0.00 & 0.00 & 0.00 & 0.00 & 0.00 & 0.00 \\
\hline Non-contr. pension & 0.00 & 0.00 & 0.00 & 0.00 & 100.00 & 0.00 \\
\hline Survivor pension & 0.00 & 0.00 & 0.00 & 0.00 & 0.00 & 0.00 \\
\hline \multicolumn{7}{|l|}{ Transitions 95-04 } \\
\hline Employment & 97.10 & 0.85 & 1.70 & 0.00 & 0.32 & 0.35 \\
\hline Job pension & 0.00 & 100.00 & 0.00 & 0.00 & 0.00 & 0.00 \\
\hline Disability pension & 0.00 & 0.00 & 100.00 & 0.00 & 0.00 & 0.00 \\
\hline Social pension & 0.00 & 0.00 & 0.00 & 0.00 & 0.00 & 0.00 \\
\hline Non-contr. pension & 0.00 & 0.00 & 0.00 & 0.00 & 100.00 & 0.00 \\
\hline Survivor pension & 0.00 & 0.00 & 0.00 & 0.00 & 0.00 & 0.00 \\
\hline \multicolumn{7}{|c|}{ B. Cohorts 1941-1950 } \\
\hline \multicolumn{7}{|l|}{ Transitions 85-95 } \\
\hline Employment & 55.68 & 39.05 & 4.00 & 0.08 & 0.16 & 1.02 \\
\hline Job pension & 0.00 & 100.00 & 0.00 & 0.00 & 0.00 & 0.00 \\
\hline Disability pension & 0.00 & 10.00 & 80.00 & 0.00 & 0.00 & 10.00 \\
\hline Social pension & 0.00 & 0.00 & 0.00 & 0.00 & 0.00 & 0.00 \\
\hline Non-contr. pension & 0.00 & 0.00 & 0.00 & 0.00 & 100.00 & 0.00 \\
\hline Survivor pension & 0.00 & 66.67 & 0.00 & 0.00 & 0.00 & 33.33 \\
\hline \multicolumn{7}{|l|}{ Transitions 95-04 } \\
\hline Employment & 9.85 & 83.42 & 2.89 & 0.80 & 0.92 & 2.12 \\
\hline Job pension & 0.06 & 99.03 & 0.03 & 0.00 & 0.03 & 0.86 \\
\hline Disability pension & 1.42 & 35.65 & 60.57 & 0.95 & 0.79 & 0.63 \\
\hline Social pension & 0.00 & 12.50 & 6.25 & 75.00 & 0.00 & 6.25 \\
\hline Non-contr. pension & 0.00 & 8.82 & 2.94 & 0.00 & 82.35 & 5.88 \\
\hline Survivor pension & 1.05 & 18.95 & 0.00 & 0.00 & 0.53 & 79.47 \\
\hline
\end{tabular}

labor force survey data provided by ISTAT through the MARSS time series. Although we cannot gain much detail of the type of nonemployment, the data allow us to distinguish different age-groups and gender for the three main components.

\subsubsection{Trends in Labor Force Status}

As previously pointed out, employment rates of men are much higher than for women, and this is a rather stable pattern for all age-groups (figure 4.23). However, younger cohorts of women have a higher employment rate and show a marked difference with respect to older cohorts. The other striking feature of figure 4.23 is that, at age sixty to sixty-four, the employment rate of men goes from 40 percent in 1977 to 30 percent in 2004. Unemployment rates are much less stable, particularly for the youngest age-group, mainly 

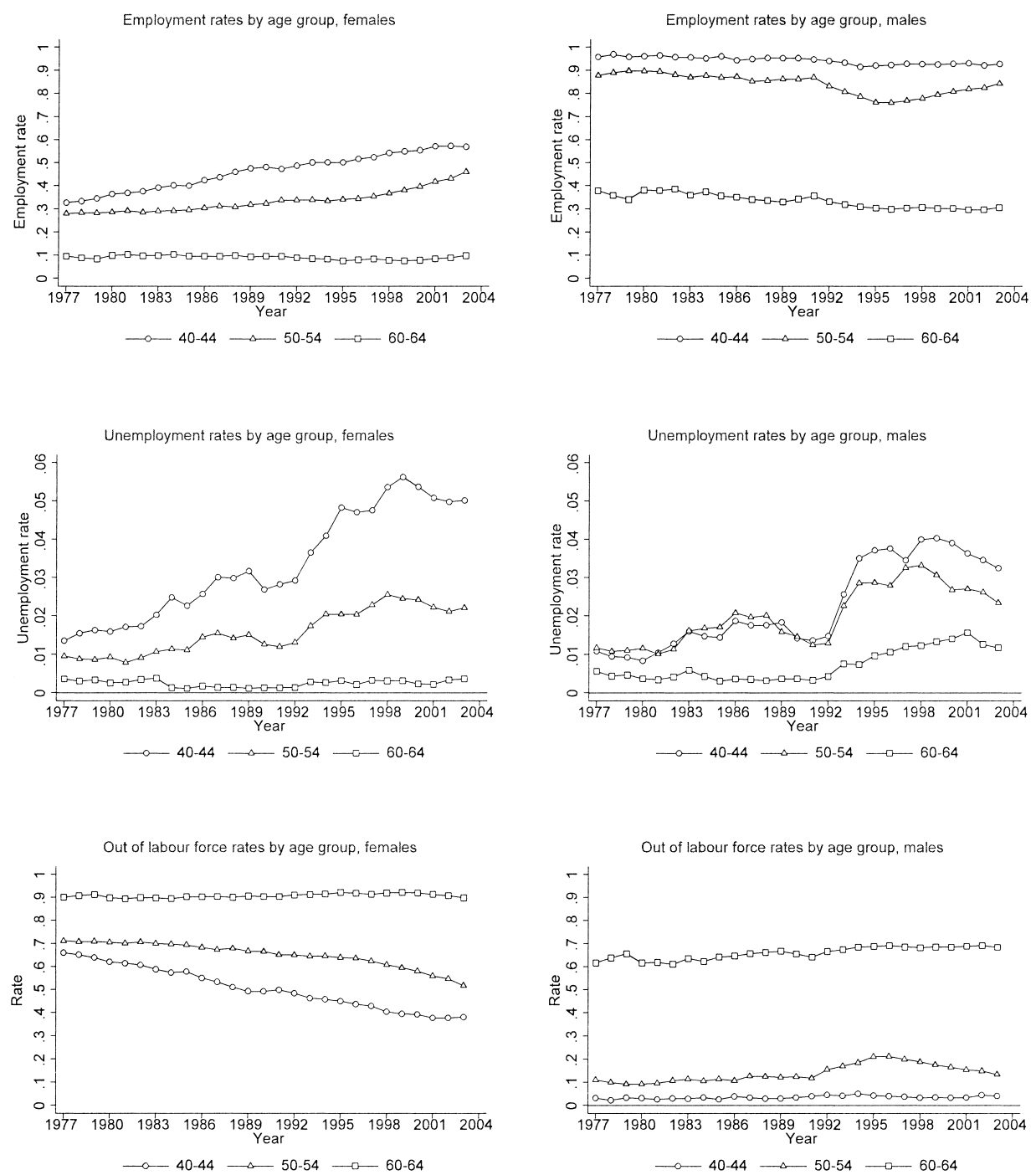

Fig. 4.23 Trends in labor force status by gender and age-group

as a result of business cycle fluctuations (see Brugiavini and Peracchi 2010). Comparing the trends in "out of the labor force" and "unemployed" rates it is clear that unemployment is not a major source component of nonemployment. Indeed the unemployment rate figures are very small, especially for the age-group sixty to sixty-four: the evidence presented in the previous sections makes clear that retirement ( particularly early retirement) has been the main explanation for exits from the labor force. Also, there seems to be nonsubstitutability between unemployment and other forms of exits at older ages. 


\subsubsection{Trends in Recipiency of DI Benefits}

In order to provide an explanation for the nonemployment patterns at older ages we look at trends in recipiency of DI benefits: we have to resort to a different data set (the INPS sample) because the labor force survey does not contain details on the type of nonemployment. Given the compelling evidence on the relevance of early retirement we present a comparison of program participation rates to disability and to early retirement. Because for the early years older individuals are underrepresented, we restrict the analysis to the period 1990 to 2004.

First it should be noted that participation rates for disability are very small. They are mostly declining over time, apart from the age-group sixty to sixty-four (figure 4.24). Participation rates to early retirement are of considerable size and increasing at all ages. This is further evidence that Italian workers transit from work to nonemployment mainly through early retirement.

A main objective of this chapter is to relate the marked changes in health conditions and survival with the labor market behavior of older workers in Italy. Because we do not have available long time series documenting trends in health conditions, we propose the following comparisons: (a) trends in mortality versus trends in disability (or early retirement), (b) heights of young men (at the medical examination for army conscripts) versus disability take up and early retirement take up, and (c) mortality rates by cause of death versus disability rates. The period of observation is 1990 to 2003.

Figure 4.25 shows once again that mortality rates are steadily declining during the period, suggesting that health conditions of the elderly improve. At the same time, disability participation rates also decline for this agegroup. However, we have shown that health improvements are not leading to higher participation in the labor market: in fact, men in that age-group exhibit strongly increasing trends in early retirement pension take up (which
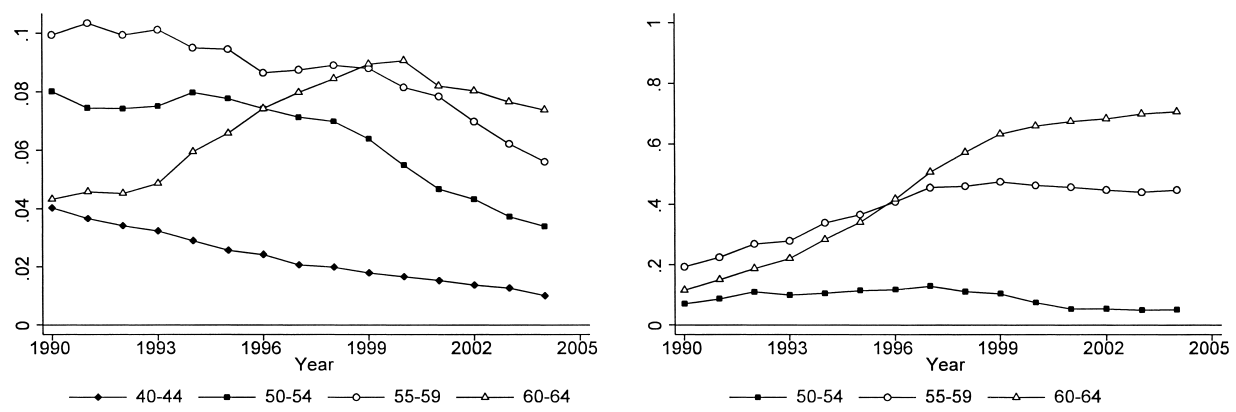

Fig. 4.24 Male participation rates to disability (left) and early retirement (right) by age-group 

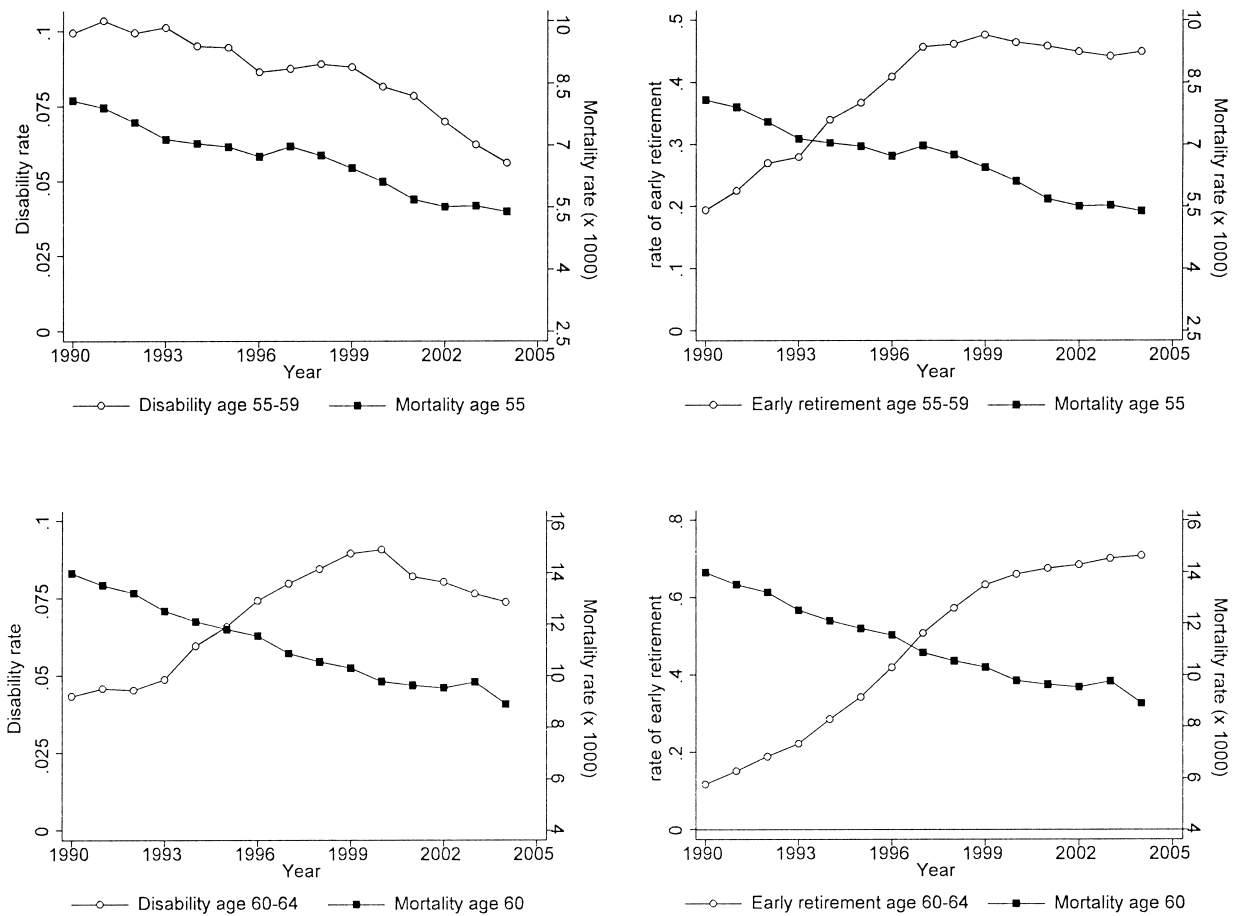

Fig. 4.25 Male mortality rates versus disability (left) and early retirement (right)

are approximately ten times higher than disability rates). For the age-group sixty to sixty-four disability rates are also increasing in the sample period, hence for this age-group more and more workers have left the labor market at a time when their life expectancy increases.

The second comparison is based on the idea that different cohorts started their lifetimes with different health stocks (as measured by height). We have available height measures of young men at the army-conscription medical test for several years (hence, cohorts), all recorded at age nineteen (see A'Hearn, Peracchi, and Vecchi 2009). ${ }^{12}$ We want to establish if the initial health stock could explain the labor market behavior later in life; of course, we cannot control for the different lifestyles and health shocks experienced by these men between age nineteen and the age at which they left the labor market.

Figure 4.26 shows that while the initial health stock increases over time for all cohorts, disability rates exhibit very unclear patterns: decreasing over time for most age-groups apart from the oldest group, sixty to sixty-four.

12. For the cohorts of men included in the sample period, serving in the army was compulsory. 

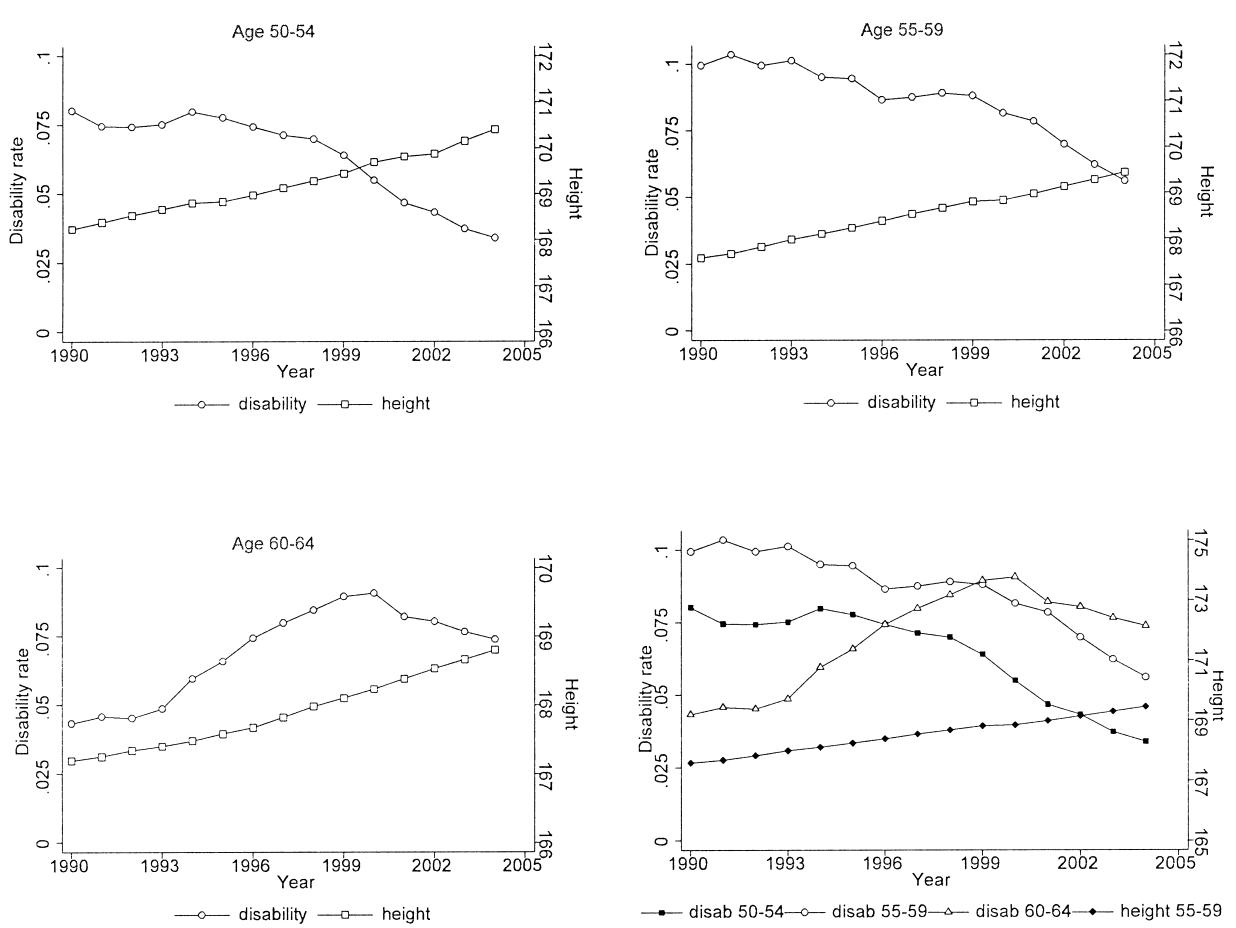

Fig. 4.26 Male height at age nineteen (in $\mathrm{cm}$ ) versus disability rates

It is hard to draw a conclusion on the actual relationship between these patterns.

Figure 4.27 provides the same evidence relating heights to early retirement participation rates. Once again we find that while health conditions (as measured by the initial health stock) improve, individuals tend to leave the labor market at higher rates.

Figure 4.28 looks at mortality rates by cause of death and early retirement rates. This is to assess whether gains due to changes in specific conditions (such as heart conditions) lead to changes in labor market behavior. Since we have provided plenty of evidence on the scarce significance of disability pensions, we focus on early retirement pensions, which are the most important exit route in Italy in the sample period. Once again the correlation is puzzling as reductions in mortality rates for important conditions (such as heart conditions) do not imply changes in early retirement participation.

\subsection{Conclusions}

This chapter describes the relationship between the characteristics of the Italian social security system (and its reforms) and the working life of 

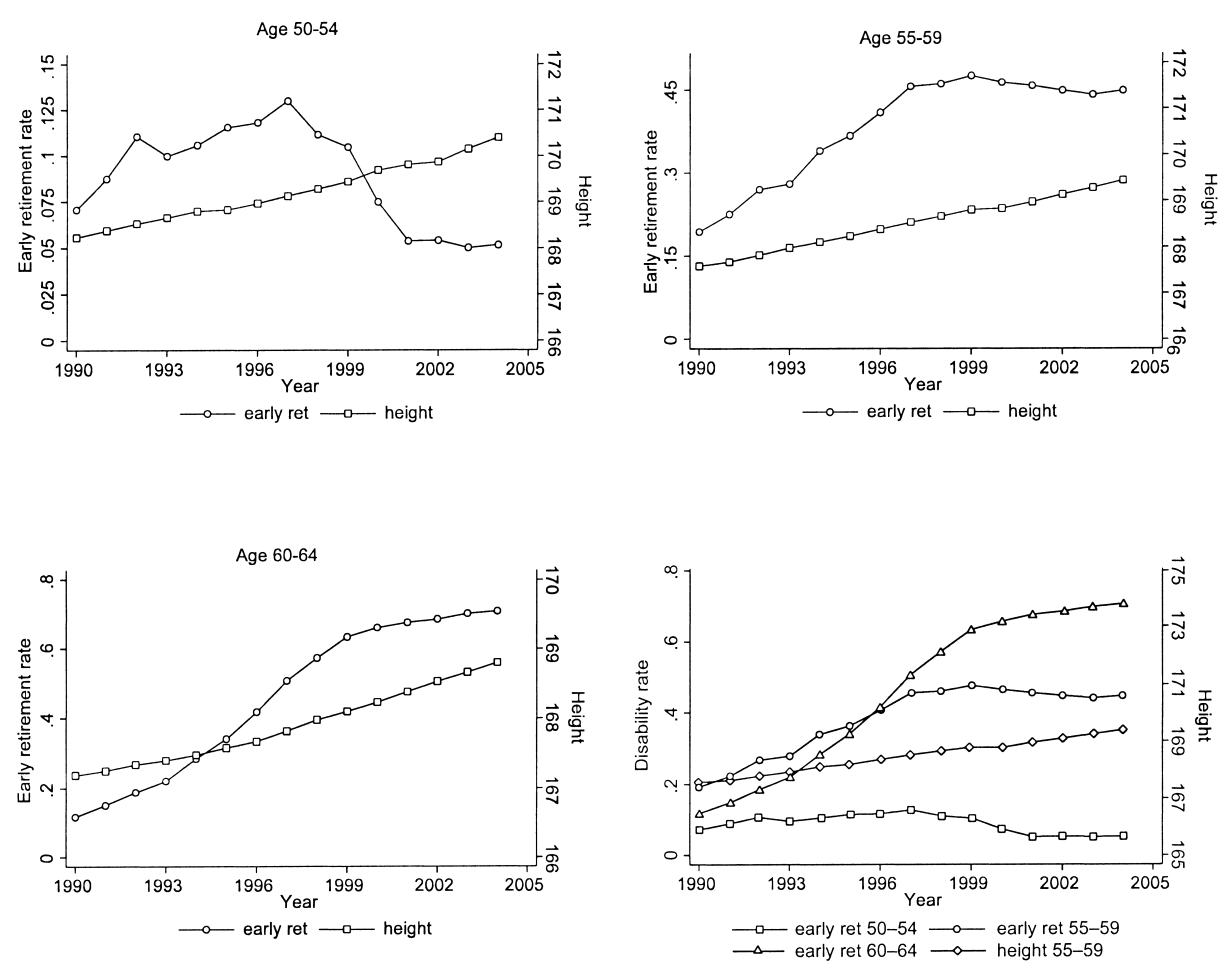

Fig. 4.27 Male height at age nineteen (in $\mathrm{cm}$ ) versus early retirement rates

individuals by considering a relevant nexus, which had been previously neglected, of these variables with trends in health conditions.

We first analyze the relevant aspects of the social security system, by focusing on the main provisions of the Italian welfare system for old-age insurance. We find that eligibility conditions for access to early retirement and old-age benefits have shaped the institutional landscape of the past decades. At the same time we present the main demographic trends in relation to mortality and health along with labor market trends (employment, unemployment, and labor force participation). The evidence points to a potential paradox: the spectacular increase in longevity experienced by the Italian population in the past decades is correlated with increasing exits from the labor force of older workers.

The historical data on mortality trends document an important increase in life expectancy and longevity. Mortality fell dramatically in Italy between 1906 and 2007. The decline in mortality evolved differently for men and women; more precisely, it was more important for women in the early decades. As a result, life expectancy increased considerably. For example, at the age of sixty it augmented by 7.6 years for men and 11.5 years for women, 

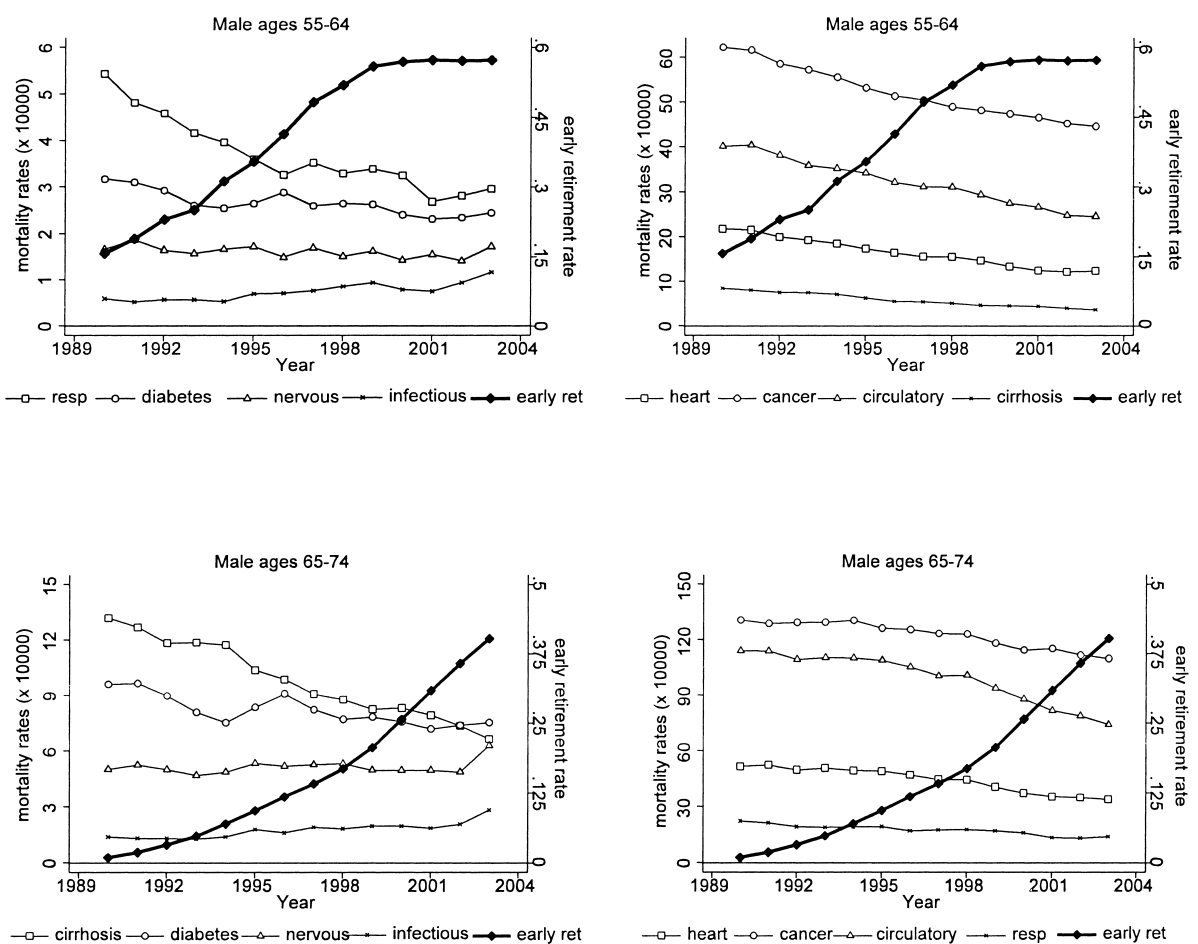

Fig. 4.28 Male mortality rates by cause of death versus early retirement rates

while at the age of eighty it improved by 3.3 years for men and 4.9 years for women. A decreasing path of the mortality is also observed at the regional level, but we remark different patterns between the three main geographical areas (North, Center, and South). In the long run these differences led to an almost total compensation of the initial existing gaps between these regions. Potential explanations for these important improvements in longevity are a better quality of the health services and a more responsible behavior at the individual level in terms of lifestyle. The reduction in mortality is to a large extent the result of the decline in mortality due to cardiovascular and respiratory diseases for men and to diabetes for women.

When looking at labor market behavior in Italy we observe that labor force participation exhibits a declining path for all workers in the age-groups fiftyfive and over, though women show very different trends from men because of cohort effects in the period 1997 to 2003. At the same time, participation in the different social security programs (old age, early retirement, disability, etc.) is dominated by retirement. For the age-groups sixty to sixty-four and fifty-five to fifty-nine old-age retirement exhibits a decreasing trend, which starts in 1992 (the date of a major pension reform). The old-age exit route is 
gradually substituted by the early retirement route, while disability increases very slightly in the same period of time.

The most striking result on the effects of the reforms of the social security system in Italy is provided by the trends in the new entries in the public pension and disability insurance, as well as by the pathways to retirement. We show that after the 1992 pension reform the prevailing exit route switched from old-age pension to the early retirement pension, especially for men who had sufficient seniority to become eligible for early retirement. The same conclusion is reached by analyzing the pathways to retirement and the transition matrices that we computed on the panel dimension of our data.

This body of evidence raises the questions of what the relationship is between health status (longevity) and the length of the working life. On the one hand, there seems to be a negative correlation between the employment rate and the mortality rate, which is much more important for men with respect to women. On the other hand, the steady decline of the mortality rates along time is accompanied by a consistent increase in the early retirement rates. Disability does not seem to play an important role in Italy.

\section{References}

A'Hearn, B., F. Peracchi, and G. Vecchi. 2009. "Height and the Normal Distribution: Evidence from Italian Military Data." Demography 46:1-25.

Attanasio, O. P., and A. Brugiavini. 2003. "Social Security and Households' Saving." Quarterly Journal of Economics 118 (3): 1075-119.

Boeri, T., and A. Brugiavini. 2009. "Pension Reforms and Women Retirement Plans." Journal of Population Ageing 1:7-30.

Bottazzi, R., T. Jappelli, and M. Padula. 2006. "Retirement Expectations, Pension Reforms, and Their Impact on Private Wealth Accumulation." Journal of Public Economics 90 (12): 2187-212.

Brugiavini, A. 2009. "Welfare Reforms and Labour Supply in Italy." Working Paper Series 2009:29. Uppsala: IFAU-Institute for Labour Market Policy Evaluation.

Brugiavini, A., and V. Galasso. 2004. "The Social Security Reform Process in Italy: Where Do We Stand?” Journal of Pension Economics and Finance 3 (2): 165-95.

Brugiavini, A., and F. Peracchi. 2004. "Micro-Modeling of Retirement Behavior in Italy." In Social Security Programs and Retirement around the World: MicroEstimation, edited by J. Gruber and D. A. Wise, 345-99. Chicago: The University of Chicago Press.

. 2007. "Fiscal Implications of Pension Reforms in Italy." In Social Security Programs and Retirement around the World: Fiscal Implications of Reforms, edited by J. Gruber and D. A. Wise, 253-94. Chicago: The University of Chicago Press. . 2010. "Youth Unemployment and Retirement of the Elderly: The Case of Italy." In Social Security Programs and Retirement around the World: The Relationship to Youth Employment, edited by J. Gruber and D. A. Wise, 167-215. Chicago: The University of Chicago Press.

Brugiavini, A., F. Peracchi, and D. Wise. 2003. "Pensions and Retirement Incentives, 
A Tale of Three Countries: Italy, Spain and USA." Giornale degli Economisti e Annali di Economia 61:131-70.

Caselli, G., and V. Egidi. 2010. "Una Vita Più Lunga e Più Sana. Riflessioni sul Passato per Immaginare il Futuro." Unpublished manuscript.

Caselli, G., F. Peracchi, E. Barbi, and L. M. Lipsi. 2003. "Differential Mortality and the Design of the Italian System of Public Pensions." Special issue, Labour 17: 45-68.

Istituto Italiano di Statistica (ISTAT). 2010. "Trattamenti Pensionistici e Beneficiari al 31 Dicembre 2008." Available at: http://www.istat.it/salastampa/comunicati/ non_calendario/20100611_00/.

Organization for Economic Cooperation and Development (OECD). 2007. Social Expenditure 1980-2003. Interpretative Guide. Available at: http://stats.oecd.org/ OECDStatDownloadFiles/_OECDSOCX2007InterpretativeGuide_En.pdf.

. 2009. Social Policy Division, Directorate of Employment, Labour and Social Affairs, Country Chapter, Benefits and Wages. Available at: http://www.oecd.org/ els/social/workincentives.

Ragioneria Generale dello Stato (RGS). 2009. Relazione Unificata sull'Economia e sulla Finanza Pubblica. Available at: http://www.rgs.mef.gov.it/VERSIONE-I/ Finanza-Pu/Relazione-1/2009/index.asp. 